\title{
Targeting Lysosomes to Reverse Hydroquinone-Induced Autophagy Defects and Oxidative Damage in Human Retinal Pigment Epithelial Cells
}

\author{
Samuel Abokyi ${ }^{1,2}{ }^{\circledR}$, Sze-Wan Shan ${ }^{1}{ }^{(0)}$, Christie Hang-I Lam ${ }^{1}$, Kirk Patrick Catral ${ }^{1}$, Feng Pan ${ }^{1,3} \mathbb{D}$, \\ Henry Ho-Lung Chan ${ }^{1,3}(\mathbb{D})$, Chi-Ho To ${ }^{1,3}$ (D) and Dennis Yan-Yin Tse ${ }^{1,3, *(D)}$ \\ 1 School of Optometry, The Hong Kong Polytechnic University, Hung Hom, Hong Kong, China; \\ samuel.abokyi@connect.polyu.hk (S.A.); samantha.shan@polyu.edu.hk (S.-W.S.); \\ christie.h.lam@connect.polyu.hk (C.H.-I.L.); kirk-patrick.catral@polyu.edu.hk (K.P.C.); \\ feng.a.pan@polyu.edu.hk (F.P.); henryhl.chan@polyu.edu.hk (H.H.-L.C.); chi-ho.to@polyu.edu.hk (C.-H.T.) \\ 2 Department of Optometry \& Vision Science, College of Health and Allied Science, University of Cape Coast, \\ Cape Coast 00233, Ghana \\ 3 Centre for Eye and Vision Research, 17W Hong Kong Science Park, Hong Kong, China \\ * Correspondence: dennis.tse@polyu.edu.hk; Tel.: +852-27666096
}

Citation: Abokyi, S.; Shan, S.-W.; Lam, C.H.-I.; Catral, K.P.; Pan, F.; Chan, H.H.-L.; To, C.-H.; Tse, D.Y.-Y. Targeting Lysosomes to Reverse Hydroquinone-Induced Autophagy Defects and Oxidative Damage in Human Retinal Pigment Epithelial Cells. Int. J. Mol. Sci. 2021, 22, 9042. https://doi.org/10.3390/

ijms22169042

Academic Editors: Janusz Blasiak and Kai Kaarniranta

Received: 16 July 2021

Accepted: 19 August 2021

Published: 22 August 2021

Publisher's Note: MDPI stays neutral with regard to jurisdictional claims in published maps and institutional affiliations.

Copyright: (c) 2021 by the authors. Licensee MDPI, Basel, Switzerland. This article is an open access article distributed under the terms and conditions of the Creative Commons Attribution (CC BY) license (https:// creativecommons.org/licenses/by/ $4.0 /)$.

\begin{abstract}
In age-related macular degeneration (AMD), hydroquinone (HQ)-induced oxidative damage in retinal pigment epithelium (RPE) is believed to be an early event contributing to dysregulation of inflammatory cytokines and vascular endothelial growth factor (VEGF) homeostasis. However, the roles of antioxidant mechanisms, such as autophagy and the ubiquitin-proteasome system, in modulating HQ-induced oxidative damage in RPE is not well-understood. This study utilized an in-vitro AMD model involving the incubation of human RPE cells (ARPE-19) with HQ. In comparison to hydrogen peroxide $\left(\mathrm{H}_{2} \mathrm{O}_{2}\right)$, HQ induced fewer reactive oxygen species (ROS) but more oxidative damage as characterized by protein carbonyl levels, mitochondrial dysfunction, and the loss of cell viability. $\mathrm{HQ}$ blocked the autophagy flux and increased proteasome activity, whereas $\mathrm{H}_{2} \mathrm{O}_{2}$ did the opposite. Moreover, the lysosomal membrane-stabilizing protein LAMP2 and cathepsin D levels declined with HQ exposure, suggesting loss of lysosomal membrane integrity and function. Accordingly, HQ induced lysosomal alkalization, thereby compromising the acidic $\mathrm{pH}$ needed for optimal lysosomal degradation. Pretreatment with MG132, a proteasome inhibitor and lysosomal stabilizer, upregulated LAMP2 and autophagy and prevented HQ-induced oxidative damage in wildtype RPE cells but not cells transfected with shRNA against ATG5. This study demonstrated that lysosomal dysfunction underlies autophagy defects and oxidative damage induced by HQ in human RPE cells and supports lysosomal stabilization with the proteasome inhibitor MG132 as a potential remedy for oxidative damage in RPE and AMD.
\end{abstract}

Keywords: age-related macular degeneration; hydroquinone; oxidative stress; autophagy; ubiquitinproteasome system (UPS); lysosomal alkalization

\section{Introduction}

Oxidative stress is a hallmark of several age-related disorders, including cardiovascular diseases, chronic obstructive pulmonary disease, chronic kidney disease, cancers, and neurodegenerative diseases [1]. Oxidative stress can lead to an accumulation of damaged and misfolded proteins and obsolete organelles, and eventually to dysregulation of cellular homeostasis and the development of human diseases [2-4]. More importantly, therefore, the quantification of reactive oxygen species (ROS) production alone is insufficient when evaluating oxidative stress because the status of the cellular antioxidative defense machinery also has to be considered [1,5].

Cellular catabolic pathways, including autophagy and the ubiquitin-proteasome system (UPS), play an antioxidative role as they regulate protein homeostasis, mitochondrial 
quality control, ROS production, and cellular adaptation [4,6]. Both pathways cooperate in maintaining proteostasis but are unique in substrate selection. The proteasome is efficient in degrading smaller and short-lived proteins, whereas larger and long-lived substrates are targeted for autophagy-lysosomal degradation [7]. Despite their unique roles in proteolysis, they are functionally connected $[7,8]$. The crosstalk and interplay between autophagy and the UPS have been described under conditions of cellular stress [7,8]. Evidence suggests that UPS inhibition can be compensated for by upregulating autophagy, but dysfunctional autophagy has been demonstrated to inhibit proteasome activity and dysregulate cellular homeostasis [7]. Moreover, upregulating proteasome activity was found to be ineffective as a protective mechanism against cellular stress mediated by impaired autophagy [7]. Therefore, depending on the changes in autophagy and proteasome activity by a compound, it may induce oxidative damage in cells or protect them against it.

The benzene metabolite hydroquinone (HQ) is an important environmental toxicant because of its widespread industrial application and health impact [9]. It has a high redox activity, resulting in increased ROS production and oxidative stress [9]. HQ exposure has also been identified as an underlying risk factor in cancerous diseases, inflammation, and neurodegenerative disorders [9]. Age-related macular degeneration (AMD), a central retinal disorder that causes visual impairment, is one of the neurodegenerative diseases for which the contribution of HQ has been well-studied. The aetiology of AMD is multifactorial, including genetic and environmental underpinnings, but it is commonly characterized by drusen and retinal pigment epithelial (RPE) abnormalities at the earliest pathophysiological stage [10]. Proteomic data from the retina of AMD donors' eyes with drusen show highly enriched oxidative protein modifications, supporting oxidative stress as an important environmental risk factor for AMD [11]. Further, epidemiological data have shown that smoking cigarettes increases the risk for RPE oxidative damage and AMD [12] and increased plasma levels of HQ almost twice compared to non-smokers [13]. Under controlled laboratory conditions, chronic exposure to cigarette smoke or HQ in mice led to oxidative damage in RPE and AMD-like pathology [14-16]. Furthermore, in vitro HQ caused oxidative damage of cultured human RPE cells, leading to dysregulated vascular endothelial growth factor (VEGF) homeostasis and increased inflammatory cytokine levels, which mirror significant events in the pathogenesis of AMD [17,18].

On the basis that human RPE cells are highly resistant to multiple pro-oxidants [19] but comparatively prone to HQ damage, we hypothesized that changes in autophagy and/or proteasome activity may underlie HQ-toxicity. An improved understanding of HQ-induced effects on cellular antioxidative pathways may lead to therapeutic strategies for RPE protection against oxidative damage and the development of AMD. In the current study, HQ inhibited autophagy and induced proteasomal activity in human RPE cells, whereas the ROS inducer $\mathrm{H}_{2} \mathrm{O}_{2}$ had the opposite effect. Autophagy inhibition by $\mathrm{HQ}$ involved downregulation of the lysosomal membrane-stabilizing protein LAMP2, lysosomal enzyme cathepsin D, and lysosomal alkalization, indicating loss of lysosomal membrane integrity and function. Proteasome inhibition with MG132, however, stabilized lysosomes, induced autophagy, and ameliorated HQ-induced oxidative damage in wildtype RPE cells but not in shRNA ATG5 transfected cells. The current study demonstrates the involvement of autophagy-lysosomal dysfunction in HQ-induced oxidative stress, suggests crosstalk between autophagy and UPS, and highlights lysosomal stabilization, via proteasome inhibition, as an interventional strategy against RPE oxidative damage and AMD.

\section{Results}

\subsection{Comparative Vulnerability of RPE Cells to HQ-Induced Oxidative Damage}

HQ has been implicated in the oxidative damage of human RPE during AMD pathogenesis $[14,16]$. To confirm the vulnerability of human RPE cells to HQ-induced oxidative stress, assays for ROS levels, protein carbonyls, and cell viability were performed on cells incubated for $2 \mathrm{~h}$ with $\mathrm{HQ}$ or $\mathrm{H}_{2} \mathrm{O}_{2}$ [20]. A 2-h incubation interval was selected to reflect the elimination half-life of $\mathrm{HQ}$ in vivo, as $\mathrm{HQ}$ is rapidly metabolized, and the parent compound 
and metabolites are largely eliminated within $1 \mathrm{~h}$ [21]. HQ doses below $25 \mu \mathrm{M}$ were used for investigating oxidative stress to avoid potential genotoxic effects of HQ that may occur at doses above $25 \mu \mathrm{M}$ [22]. Moreover, this dose range corresponds with available data on $\mathrm{HQ}$ levels in the blood after benzene/HQ exposure [23]. Literature data indicate that the highest $\mathrm{H}_{2} \mathrm{O}_{2}$ level measured in human tissue or blood is about $35 \mu \mathrm{M}$ [24]. However, we used up to $500 \mu \mathrm{M} \mathrm{H}_{2} \mathrm{O}_{2}$ because earlier reports and our preliminary studies suggested the relative resistance of human RPE cells to $\mathrm{H}_{2} \mathrm{O}_{2}$-induced oxidative stress [19]. Both $\mathrm{HQ}$ and $\mathrm{H}_{2} \mathrm{O}_{2}$ caused dose-dependent increases in ROS levels, protein carbonyl levels, and the loss of cell viability in RPE cells (Figure 1A,B). Interestingly, while HQ-induced elevation of ROS levels was notably much lower than with $\mathrm{H}_{2} \mathrm{O}_{2}$ (Figure $1 \mathrm{~A}, \mathrm{~B}$ ), $\mathrm{HQ}$ induced higher protein carbonyl levels and loss of viability (Figure 1B). For instance, $62.5 \mu \mathrm{M} \mathrm{H}_{2} \mathrm{O}_{2}$ generated a significant increase in ROS levels yet caused little or no effect on the protein carbonyl levels and cell viability. In contrast, $20 \mu \mathrm{M} H Q$ generated a comparable increase in ROS levels and at the same time caused a significant increase in protein carbonyl levels $(p<0.001$, one-way ANOVA) and loss of cell viability ( $p<0.001$; one-way ANOVA; Figure 1B). These results confirmed the relative vulnerability of RPE cells to HQ-induced stress.
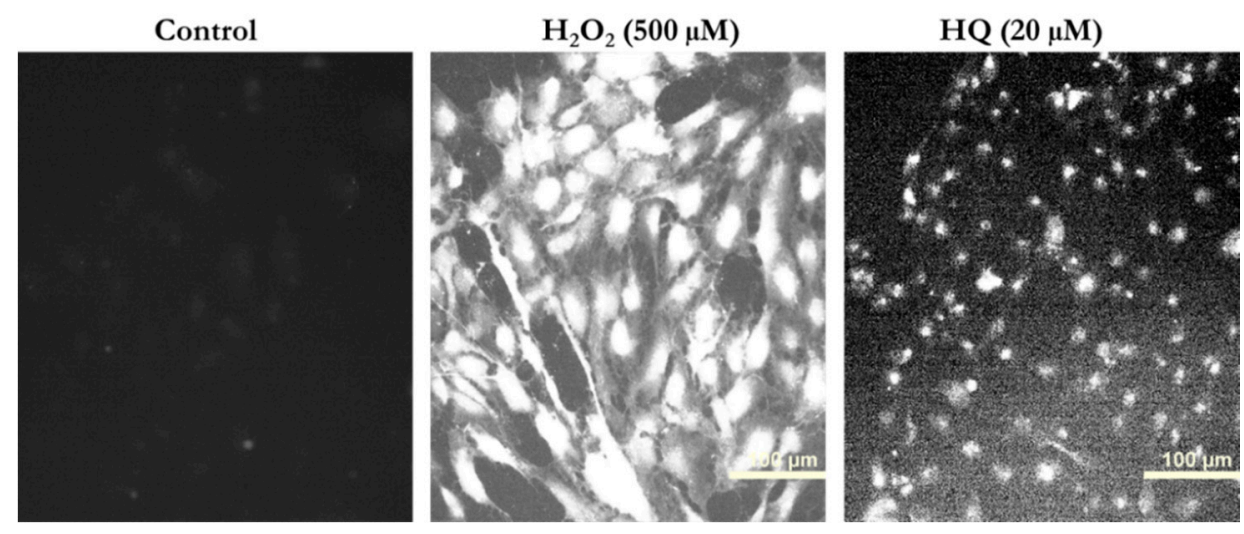

(A)
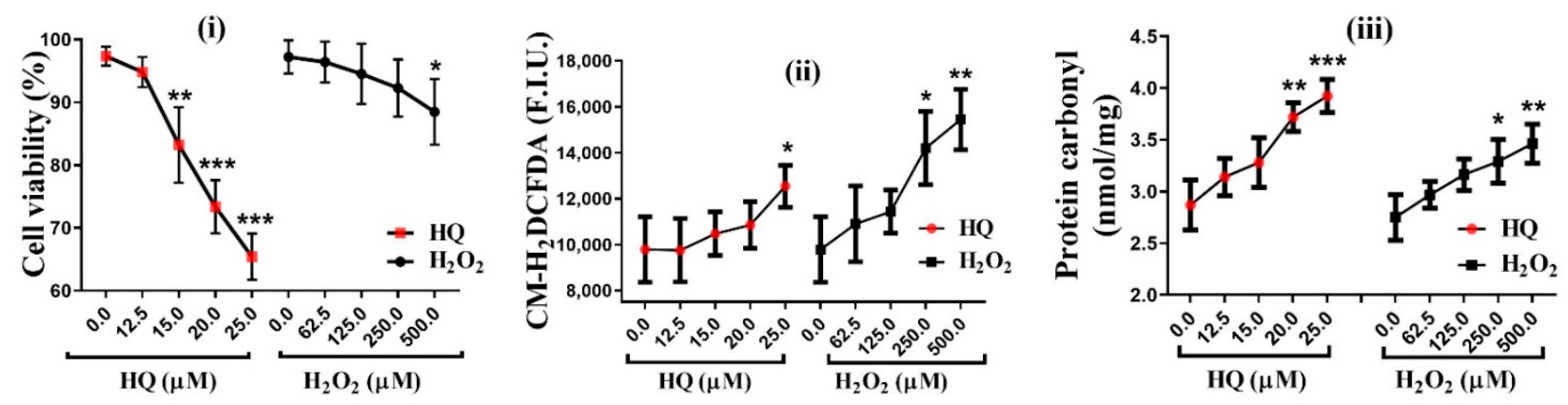

(B)

Figure 1. ARPE-19 cells are vulnerable to hydroquinone (HQ)-induced oxidative damage. (A) Live-cell confocal microscopy for intracellular reactive oxygen species (ROS) using CM-H2DCFDA dye after incubation of cells with $\mathrm{HQ}_{\text {or }} \mathrm{H}_{2} \mathrm{O}_{2}$ for $2 \mathrm{~h}$. Basal ROS level in the control is barely visible compared to $\mathrm{H}_{2} \mathrm{O}_{2}$ treatment or HQ upon calibration. (B) Quantification of the (i) cell viability by Trypan blue dye exclusion assay, (ii) ROS levels, and (iii) protein carbonyl levels by fluorescent spectrometry using a microplate reader following incubation with $\mathrm{HQ}$ or $\mathrm{H}_{2} \mathrm{O}_{2}$ for $2 \mathrm{~h}$. Data represent the mean (+standard deviation, SD) of 3 independent experiments of 3 replicates each. Statistical analysis was performed by one-way ANOVA followed by Dunnett's multiple comparison tests. ${ }^{*} p<0.05,{ }^{* *} p<0.01,{ }^{* * *} p<0.001$, significant difference relative to the controls. Fluorescence intensity units (F.I.U.). 


\subsection{HQ-Induced Mitochondrial Dysfunction}

The mitochondrion is a primary source of intracellular ROS and, therefore, is affected early in oxidative stress-mediated cell death [25]. To demonstrate that oxidative stress was involved in HQ-induced RPE damage, we examined the impact of HQ on the mitochondrial morphology and mitochondrial membrane potential of RPE cells. Healthy mitochondria exist as a dynamic network of an interconnected tubular structure, and a compromise of the mitochondrial function distorts this arrangement, resulting in altered connectivity and formation of short, round mitochondria [26]. Moreover, the mitochondrial membrane potential is directly correlated with ATP production because it reflects the process of electron transport and oxidative phosphorylation [27]. Our results showed that cells incubated with $\mathrm{HQ}$ had marked disorganization of the mitochondrial network compared with control RPE cells (Figure 2A). Further, HQ exposure led to a significant reduction in the mitochondrial membrane potential of human RPE cells (Figure 2B), in agreement with recent studies [28]. While $\mathrm{H}_{2} \mathrm{O}_{2}$-treated cells also showed some changes in the mitochondrial network morphology (Figure 2A), the mitochondrial membrane potential remained unaffected after treatment with up to $500 \mu \mathrm{M} \mathrm{H}_{2} \mathrm{O}_{2}$ (Figure 2B), confirming the relative resistance of RPE cells against $\mathrm{H}_{2} \mathrm{O}_{2}$-induced damage. These data, therefore, underpin oxidative stress as the underlying cause of HQ-induced RPE damage.
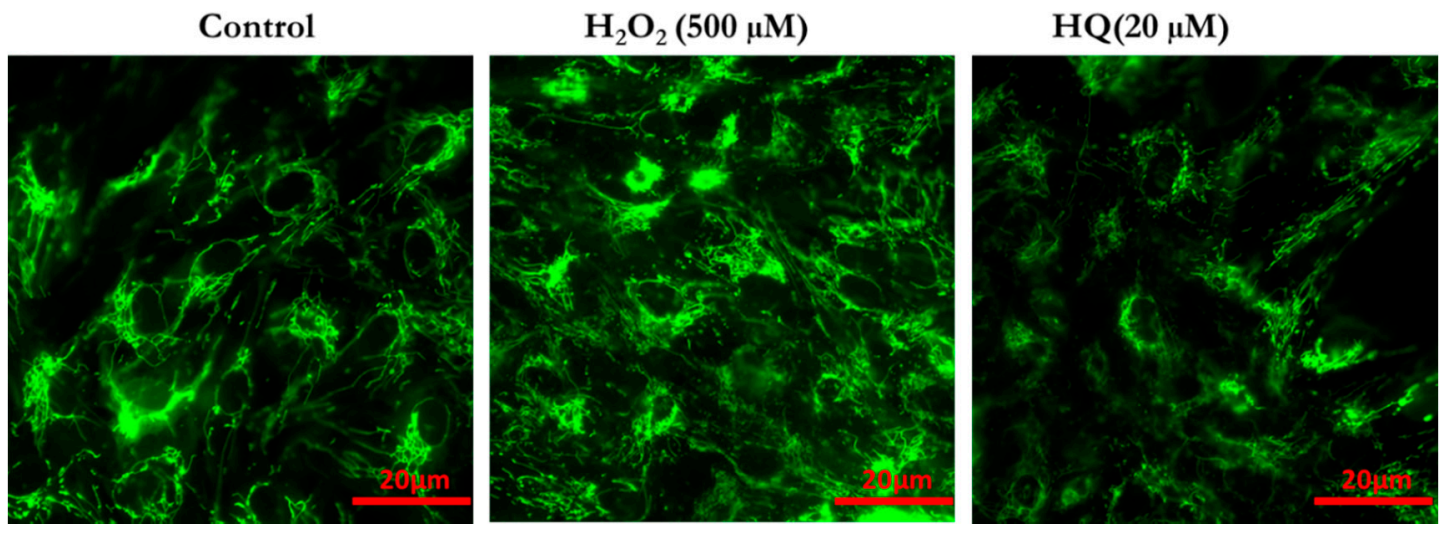

(A)

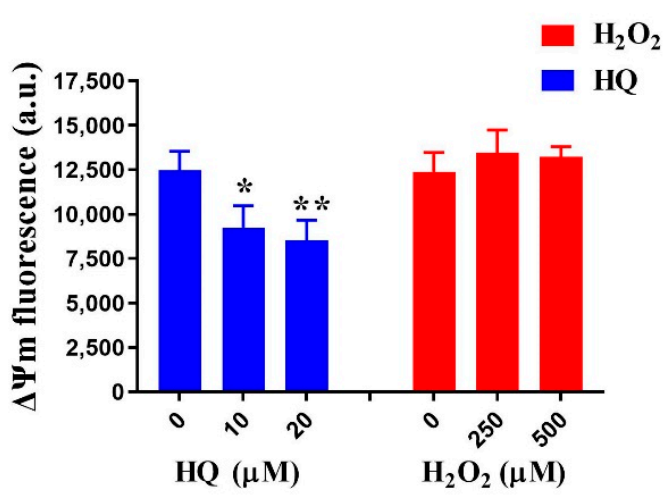

(B)

Figure 2. Effects of hydroquinone (HQ) and $\mathrm{H}_{2} \mathrm{O}_{2}$ on mitochondrial morphology and mitochondrial membrane potential. (A) Live-cell fluorescence microscopy with the MitoTracker Green FM dye to determine changes in mitochondrial morphology in cells after incubation with $\mathrm{HQ}$ or $\mathrm{H}_{2} \mathrm{O}_{2}$ for $2 \mathrm{~h}$. (B) Measurement of mitochondrial membrane potential using TMRE dye in cells after treatment with $\mathrm{HQ}$ or $\mathrm{H}_{2} \mathrm{O}_{2}$ for $2 \mathrm{~h}$ and using a fluorescence microplate reader at excitation/emission of $549 \mathrm{~nm} / 575 \mathrm{~nm}$. Data represent the mean (+standard deviation, SD) of 3 independent experiments of 3 replicates each. Statistical analysis was performed by one-way ANOVA followed by Dunnett's multiple comparison tests. ${ }^{*} p<0.05$, ** $p<0.01$, significant difference relative to the controls. Arbitrary unit (a.u.). 


\subsection{HQ Impairs Autophagy Flux in RPE Cells}

The autophagy-lysosomal pathway (ALP) participates in the cellular response to oxidative stress through the degradation of oxidized proteins, lipids, and damaged mitochondria, particularly in post-mitotic cells [4]. We investigated the role of the ALP in HQand $\mathrm{H}_{2} \mathrm{O}_{2}$ induced toxicity on RPE cells. Autophagosomes are double-membrane vesicles that sequester intracellular substrates for lysosomal degradation [29]. Their membrane contains lapidated, membrane-bound LC3 protein (LC3-II), a commonly used marker for autophagosomal staining. In transfected RPE cells expressing GFP-LC3, HQ and $\mathrm{H}_{2} \mathrm{O}_{2}$ increased the number of autophagosomes, as demonstrated by increased numbers of GFPLC3 puncta, which reflect clusters of LC3-II in autophagosomes (Figure 3A). Furthermore, we observed that the endogenous LC3-II level increased dose-dependently when cells were treated with $\mathrm{HQ}$ (Figure 3B). At concentrations up to $250 \mu \mathrm{M}, \mathrm{H}_{2} \mathrm{O}_{2}$ also dose-dependently increased LC3-II, but at $500 \mu \mathrm{M}, \mathrm{H}_{2} \mathrm{O}_{2}$ caused LC3-II to decline (Figure 3C). [30]. Since the net formation and degradation of autophagosomes (or LC3-II) determine its expression level in a cell, an increase in autophagosome number (or LC3-II) may indicate autophagy upregulation or the block of autophagy flux $[30,31]$.

To determine if altered protein levels of LC3-II after treatment with $\mathrm{HQ}$ and $\mathrm{H} 2 \mathrm{O} 2$ were due to changes in the rate of autophagosome formation or lysosomal degradation the exact role of autophagy, we assessed the levels of LC3-II in the presence of the lysosomal inhibitor chloroquine (CQ), which blocks the later stage of autophagy flux, thereby facilitating selective quantification of treatment-induced autophagosome (or LC3-II) formation [32]. When the autophagy flux is blocked by CQ, an additional increase in LC3-II levels by a drug will indicate autophagosome induction. As expected, treatment of the RPE cells with $50 \mu \mathrm{M}$ CQ for $8 \mathrm{~h}$ resulted in a dramatic increase in LC3-II levels compared to the control (Figure 3D) due to the inhibition of basal autophagy and LC3-II degradation [33]. Following CQ treatment, additional treatment with HQ did not affect LC3-II protein levels, indicating that $\mathrm{HQ}$ did not alter autophagosome formation but likely reduced autophagosome flux (Figure 3D). In stark contrast, co-incubation with $\mathrm{H}_{2} \mathrm{O}_{2}$ and CQ led to increased LC3-II levels relative to treatment with CQ alone (Figure 3E), indicating $\mathrm{H}_{2} \mathrm{O}_{2}$-induced upregulation of autophagosome formation. In RPE cells and other cell types, autophagy upregulation was found to be protective against $\mathrm{H}_{2} \mathrm{O}_{2}$-induced oxidative damage [34,35]. The $\mathrm{H}_{2} \mathrm{O}_{2}$-mediated induction of autophagosome formation and flux may explain comparatively lower protein carbonyl levels and mitochondrial dysfunction after $\mathrm{H}_{2} \mathrm{O}_{2}$ treatment, relative to $\mathrm{HQ}$ treatment, despite $\mathrm{H}_{2} \mathrm{O}_{2}$ leading to more ROS formation. Together, these results demonstrated that $\mathrm{HQ}$, unlike $\mathrm{H}_{2} \mathrm{O}_{2}$, inhibited autophagy in human RPE cells, and relative to $\mathrm{H}_{2} \mathrm{O}_{2}$, CQ dysregulates cellular homeostasis more potently.

\subsection{HQ Does Not Downregulate TFEB or Downstream Autophagy Genes}

TFEB is the master transcription factor coordinating autophagy and lysosomal biogenesis through transcriptional regulation of a network of genes known as the CLEAR network [36]. Hence, to fully elucidate the role of HQ on the ALP, we sought to determine whether impaired TFEB activity was involved. TFEB activation leads to its nuclear translocation and binding to the promoter regions of the CLEAR network, resulting in TFEB overexpression and autophagy induction [37]. Expression levels of TFEB as well as its downstream target genes (including ATG5 and ATG7 involved in autophagosome formation) are good indicators of TFEB activity and, therefore, were evaluated. The data revealed that HQ elevated the protein expression of TFEB (Figure 4A) and the mRNA levels of ATG5 and ATG7 (Figure 4B). These data rule out HQ-mediated dysregulation of autophagy at the transcriptional level. 

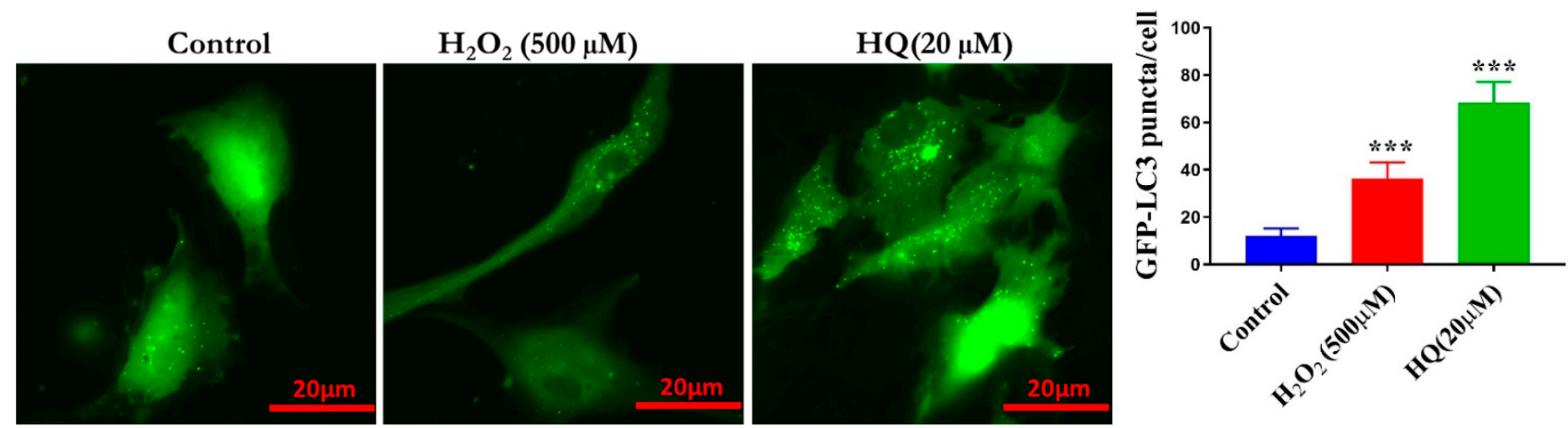

(A)
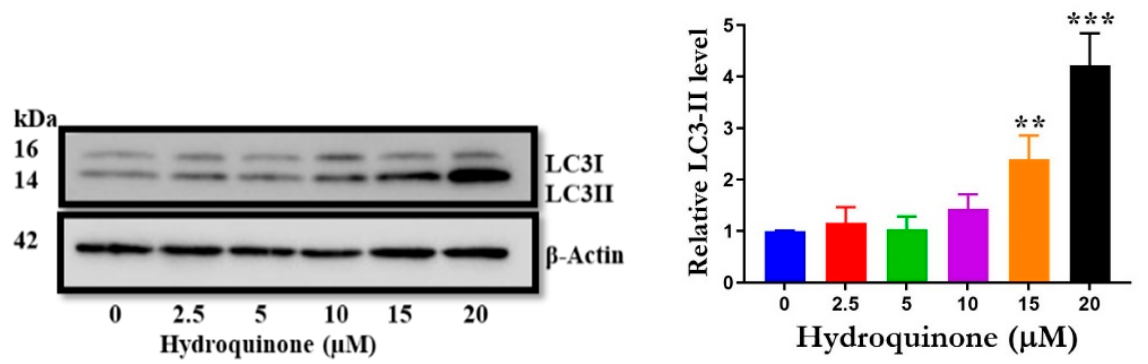

(B)
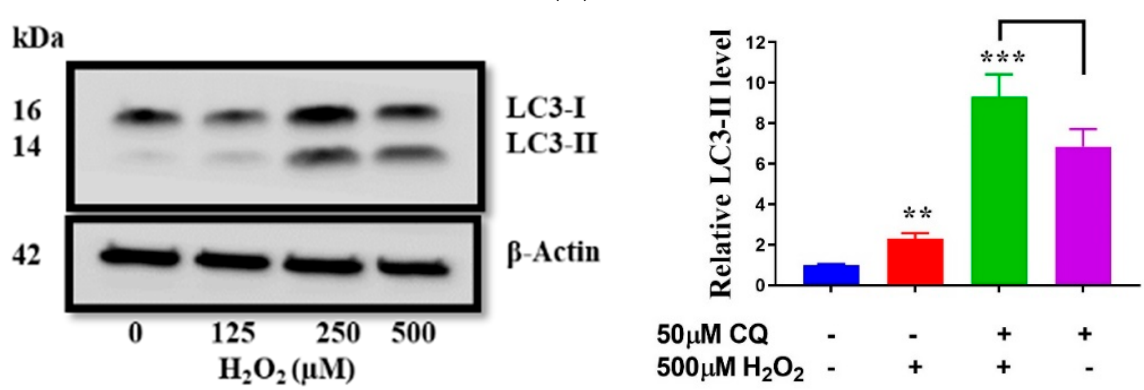

(C)
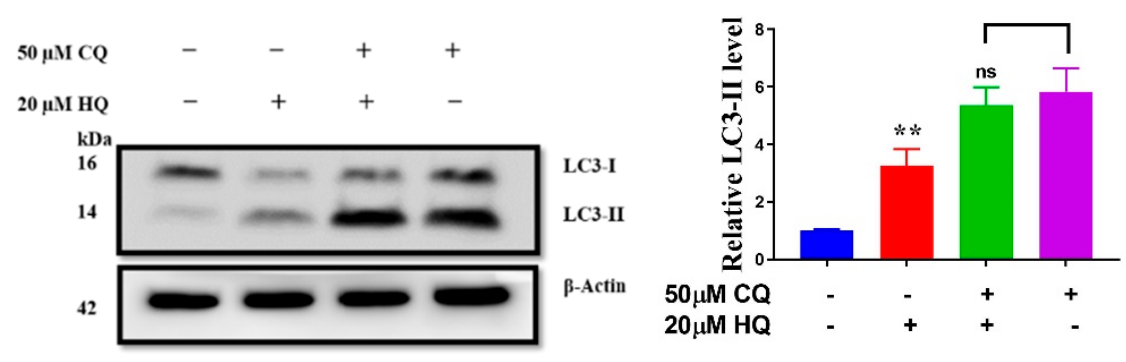

(D)

Figure 3. Cont. 

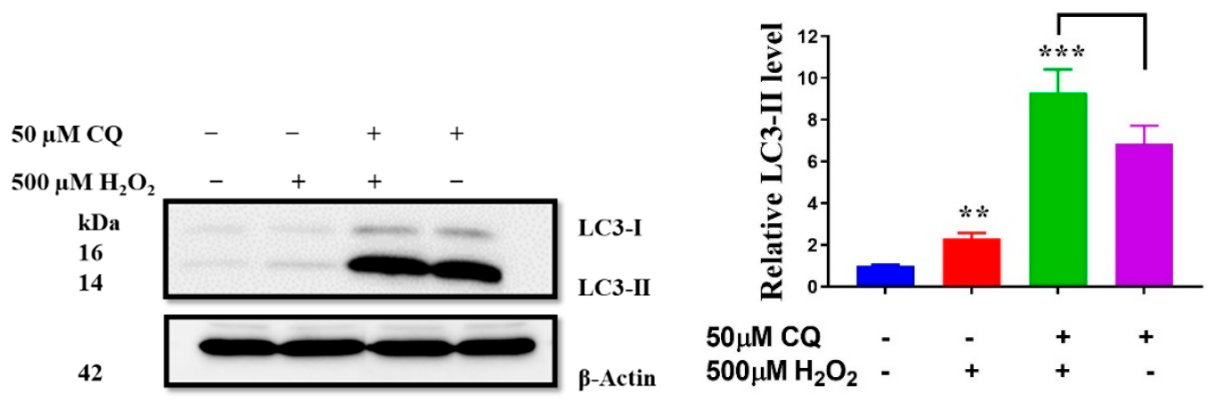

(E)

Figure 3. Differential effects of hydroquinone (HQ) and $\mathrm{H}_{2} \mathrm{O}_{2}$ on autophagy flux in ARPE-19 cells. (A) Increased GFP-LC3 puncta indicating the accumulation of autophagosomes in cells transfected with the GFP-LC3 plasmid and incubated with $\mathrm{HQ}$ or $\mathrm{H}_{2} \mathrm{O}_{2}$ for $2 \mathrm{~h}$. (B,C) Immunoblot showing a dose-dependent increase in the autophagy marker LC3-II in ARPE-19 cells treated with $\mathrm{HQ}$ or $\mathrm{H}_{2} \mathrm{O}_{2}$ for $2 \mathrm{~h}$. (D,E) Autophagy flux in cells with chloroquine (CQ) pretreatment for $8 \mathrm{~h}$, followed by incubating with $\mathrm{HQ}$ or $\mathrm{H}_{2} \mathrm{O}_{2}$ for $2 \mathrm{~h}$. Densitometry quantification of protein levels was normalized with $\beta$-actin and expressed as a ratio relative to the control. Data represent the mean + SD of 3 independent experiments of 3 replicates each. Statistical analysis using one-way ANOVA followed by Sidak or Dunnett's multiple comparison test. ${ }^{* *} p<0.01$, *** $p<0.001$ vs. control, significant difference relative to the controls.

\subsection{HQ Downregulates LAMP2 and Cathepsin D Expression}

Autophagy inhibition resulting in autophagosome (or LC3-II) accumulation may arise from deficits in the autophagosome-lysosome fusion and/or lysosomal degradation [38]. Hence, we determined whether HQ impaired lysosomal function by monitoring changes in the lysosome membrane protein LAMP2, which is integral in the control of autolysosome formation and degradation of autophagosomes [38,39]. We found that $\mathrm{HQ}$ treatment led to a decline in LAMP2 levels in a dose-dependent manner (Figure 4C), suggesting that HQ impaired lysosomal function in RPE cells.

The lysosomal aspartic protease cathepsin D is also a relevant indicator of lysosomal activity as it is involved in proteolytic degradation of autophagy substrate [40]. LAMP2 downregulation affects cathepsin D since the former is involved in the trafficking of the latter to lysosomes via endosomes after synthesis by the rough endoplasmic reticulum and Golgi complex $[39,40]$. Moreover, LAMP2 deficiency also leads to the loss of lysosomal membrane integrity, resulting in reduced retention of cathepsin D within the lumen [41]. Given the intimate relationship between LAMP2 and cathepsin D, we determined the effect of HQ on cathepsin D protein expression in RPE cells. Consistent with reduced LAMP2 expression, the cathepsin D levels also dose-dependently decreased following HQ treatment (Figure 4D), suggesting that dysregulated LAMP2 expression also affected cathepsin D expression and lysosomal homeostasis.

\subsection{HQ Induces Lysosomal Alkalization}

Intra-lysosomal enzymes involved in substrate degradation function optimally within a narrow range of acidic $\mathrm{pH}$ values [42,43]. Therefore, lysosome-alkalizing substances significantly impair lysosomal function and autophagy. Alteration of the lysosomal $\mathrm{pH}$ affects both autophagy and the phagocytic RPE functions [42]. The effect of HQ on the intra-lysosomal $\mathrm{pH}$ was determined using a ratiometric probe that changed from blue to yellow fluorescence with increasing acidity. While the exposure of cells to $62.5 \mu \mathrm{M} \mathrm{H}_{2} \mathrm{O}_{2}$, about twice the physiological concentration of $\mathrm{H}_{2} \mathrm{O}_{2}$ found in the body, did not affect the lysosomal $\mathrm{pH}, \mathrm{HQ}$ at concentrations as low as $2.5 \mu \mathrm{M}$ significantly increased the luminal $\mathrm{pH}$ to 5.6 compared with the control 5.1 (Figure 5A, $p<0.001$, one-way ANOVA, Dunnett's post hoc test). Thus, exposure of RPE cells to HQ may cause lysosomal dysfunction through the loss of lysosomal membrane integrity (i.e., downregulation of LAMP2 and cathepsin D levels) and lysosomal alkalization. 

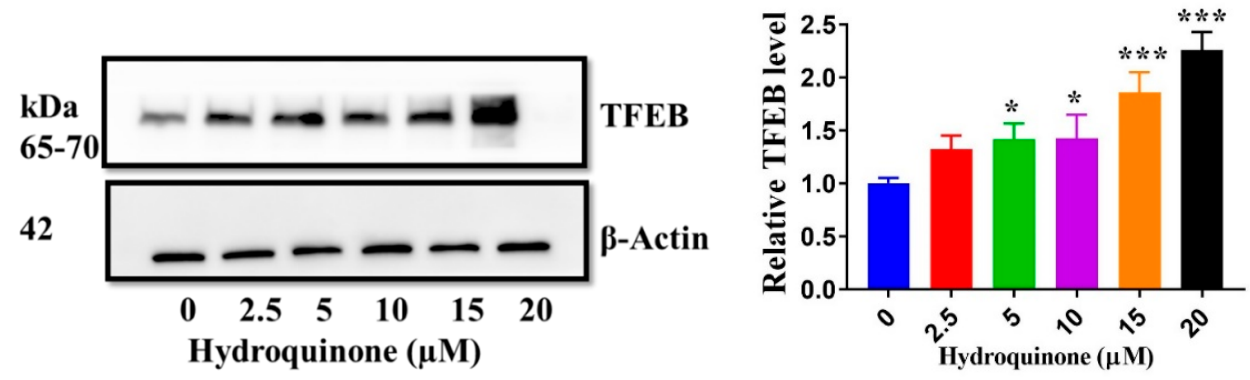

(A)

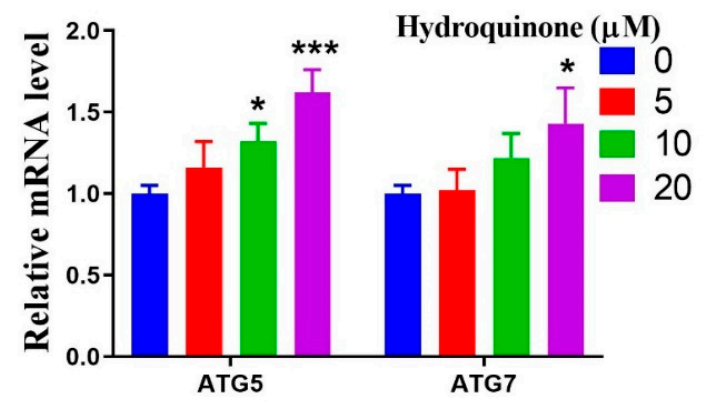

(B)
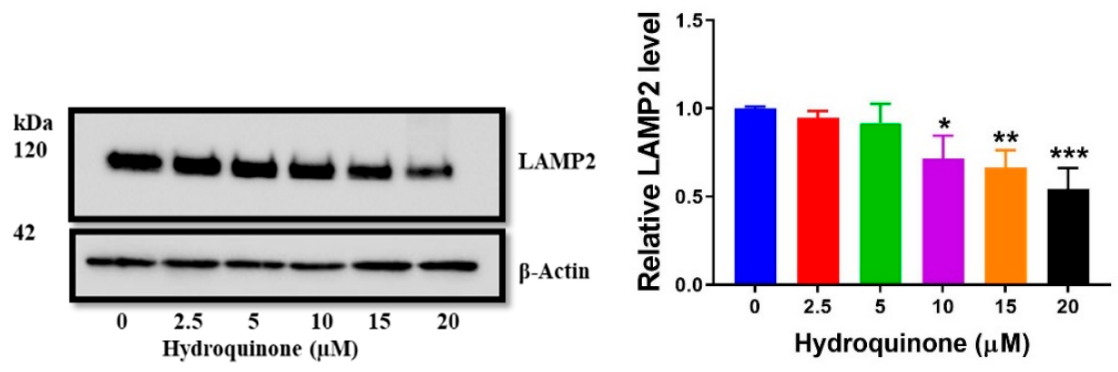

(C)
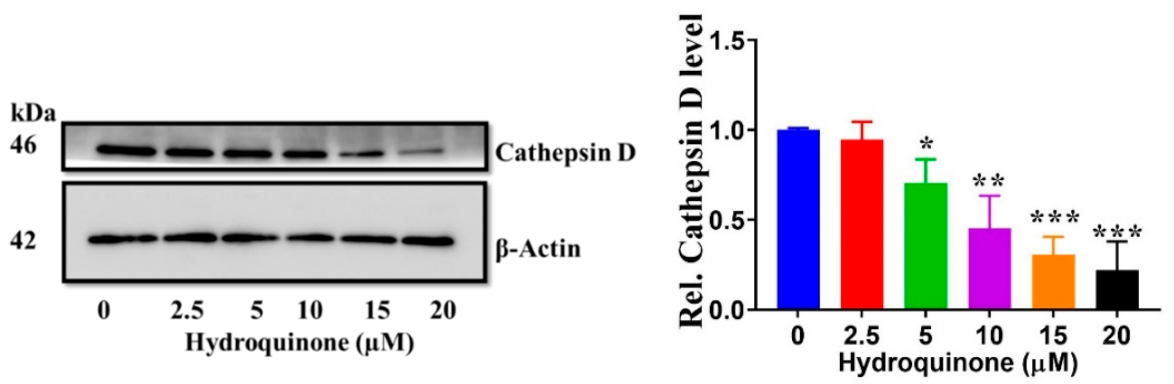

(D)

Figure 4. Effect of hydroquinone (HQ) on mRNA and protein markers of the autophagy-lysosomal pathway. (A,B) Overexpression of TFEB protein and elevated mRNA levels of ATG5 and ATG7 in ARPE-19 incubated with HQ for $2 \mathrm{~h}$. (C,D) Immunoblots for LAMP2 and cathepsin D levels in whole-cell lysate from cells exposed to HQ for $2 \mathrm{~h}$. Densitometric quantification of protein levels was normalized to $\beta$-actin and expressed as a ratio of the control. Data represent the mean + SD of 3 independent experiments of 3 replicates each. Statistical analysis using one-way ANOVA followed by Dunnett's multiple comparison test. ${ }^{*} p<0.05,{ }^{* *} p<0.01,{ }^{* * *} p<0.001$, significant difference relative to the controls. 


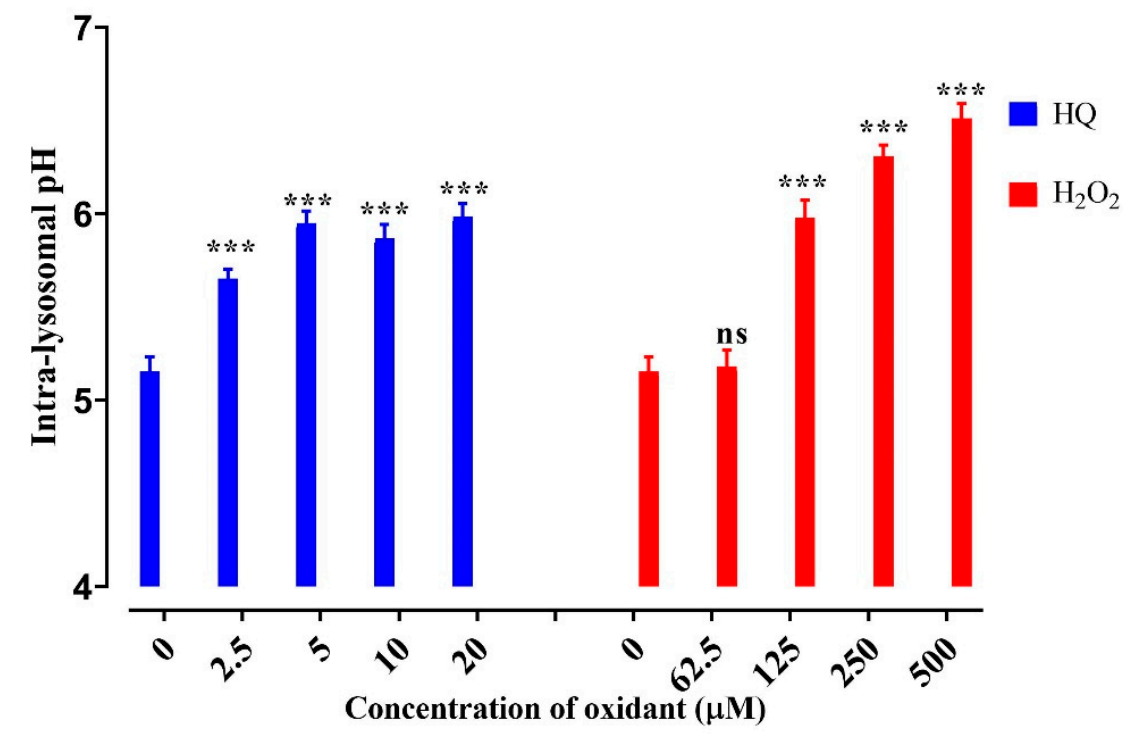

(A)

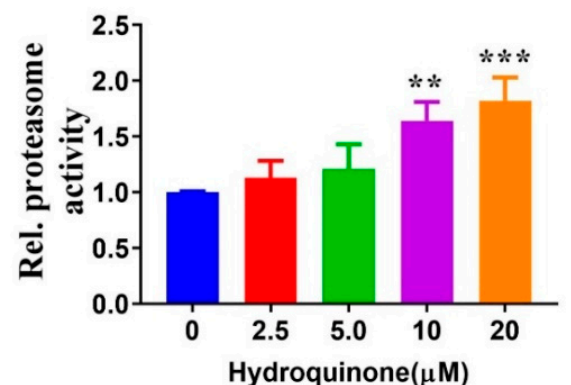

(B)

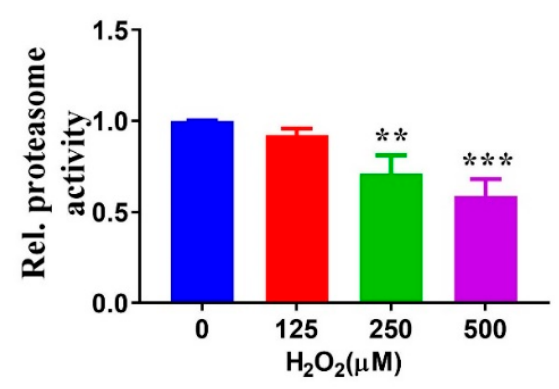

(C)

Figure 5. Effect of oxidants on lysosomal $\mathrm{pH}$ and proteasome activity. (A) Measurement of intra-lysosomal $\mathrm{pH}$ using LysoSensor ${ }^{\mathrm{TM}}$ Yellow/Blue DND-160 in ARPE-19 cells plated in 96-well plates and incubated with $\mathrm{HQ}$ or $\mathrm{H}_{2} \mathrm{O}_{2}$ for $2 \mathrm{~h}$. $(B, C)$ Proteasome activity using a fluorogenic substrate for detection of chymotrypsin-like activity in cells treated with $\mathrm{HQ}$ or $\mathrm{H}_{2} \mathrm{O}_{2}$ for $2 \mathrm{~h}$. Data represent the mean $+\mathrm{SD}$ of 3 independent experiments of 3 replicates each. Statistical analysis using one-way ANOVA followed by Dunnett's multiple comparison test. ${ }^{* *} p<0.01,{ }^{* * *} p<0.001$, significant difference relative to the controls.

\subsection{HQ Upregulates Proteasome Activity in RPE Cells}

Crosstalk between autophagy and the UPS is observed in many systems [7,8]. Inhibition of proteasome activity increases autophagy, supporting a compensatory regulation between these pathways under cellular stress conditions [44,45]. We therefore assessed the interplay between autophagy and UPS under oxidative stress using $\mathrm{HQ}$ and $\mathrm{H}_{2} \mathrm{O}_{2}$. We found that the two oxidants affected proteasome activity differently as HQ-treated cells showed increased proteasome activity (Figure 5B) whereas $\mathrm{H}_{2} \mathrm{O}_{2}$-treated cells had a decline in proteasome activity (Figure $5 \mathrm{C}$ ). Our data confirm compensatory regulation between autophagy and UPS under oxidative stress in RPE cells with $\mathrm{H}_{2} \mathrm{O}_{2}$ causing proteasome and increased autophagy, and HQ treatment causing the opposite effect, consistent with literature findings [44]. However, these results challenge an earlier hypothesis that proteasome inactivation was a crucial event in the oxidative damage of RPE cells $[46,47]$. Our data demonstrated that compensatory proteasome activation in autophagy-deficient HQ-treated cells did not provide effective protection against oxidative stress.

\subsection{MG132 Stabilizes Lysosomes, Improves Autophagy, and Protects against Oxidative Damage}

Recently, the peptide aldehyde proteasome inhibitor MG132 was found to stabilize the lysosomal membrane, restore lysosomal $\mathrm{pH}$ homeostasis, and induce autophagy in 
macrophages [48]. In addition, MG132 was shown to enhance cathepsin D activity and elevate LAMP1 levels [45]. Therefore, we tested MG132 in HQ-treated RPE cells. Firstly, we performed a dose-response study to investigate the effect of MG132 on proteasome activity, ROS generation, and apoptosis in ARPE-19 cells. We observed that MG132 inhibited proteasome activity dose-dependently from $2.5 \mu \mathrm{M}$ to $10 \mu \mathrm{M}$ (Figure $6 \mathrm{~A}$ ) without affecting ROS levels (data not shown), compared with the solvent control (i.e., ethanol). However, we found that treating cells with $10 \mu \mathrm{M}$ MG132 induced apoptosis in RPE cells (Figure 6B).

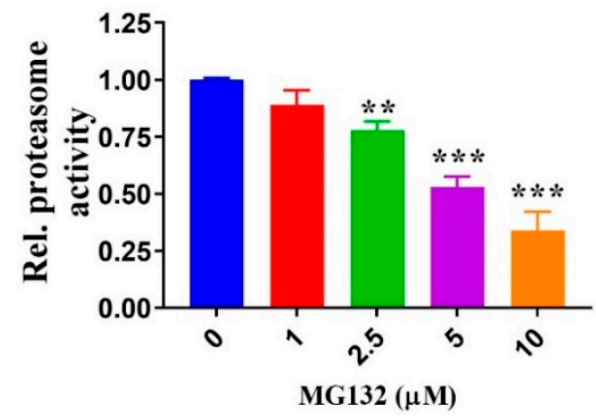

(A)
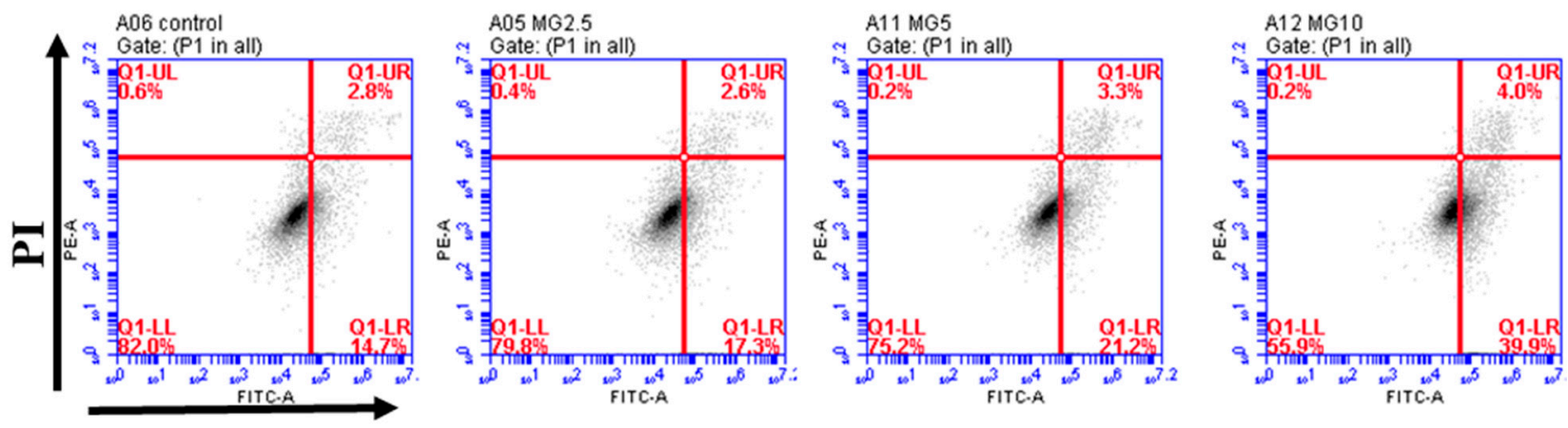

AV FITC

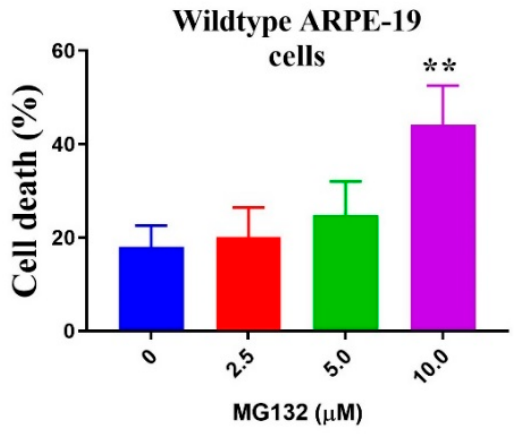

(B)

Figure 6. Effect of MG132 on proteasome inhibition and apoptosis in ARPE-19 cells. (A) Proteasome activity declines dose-dependently in cells treated with MG132 for 5 h. (B) Annexin V-FITC/PI staining to assess cell death after treatment with MG132 or vehicle (control) for $5 \mathrm{~h}$. Data represent the mean (+SD) of 3 independent experiments of 3 replicates each. Statistical analysis using one-way ANOVA followed by Dunnett's multiple comparison test. ${ }^{* *} p<0.01,{ }^{* *} p<0.001$, significant difference relative to the controls. 
Next, we assessed the effect of MG132 on autophagy in human RPE cells. Our results demonstrated that MG132 treatment increased LC3-II in a dose-dependent manner including in the presence of CQ (Figure 7A,B), consistent with MG132 increasing autophagosome formation. Moreover, MG132 upregulated LAMP2, a lysosomal membrane protein involved in lysosomal stabilization and homeostasis (Figure 7C). Thus, our results corroborated the efficacy of MG132 in the stabilization of lysosomes and induction of autophagy $[45,48]$.
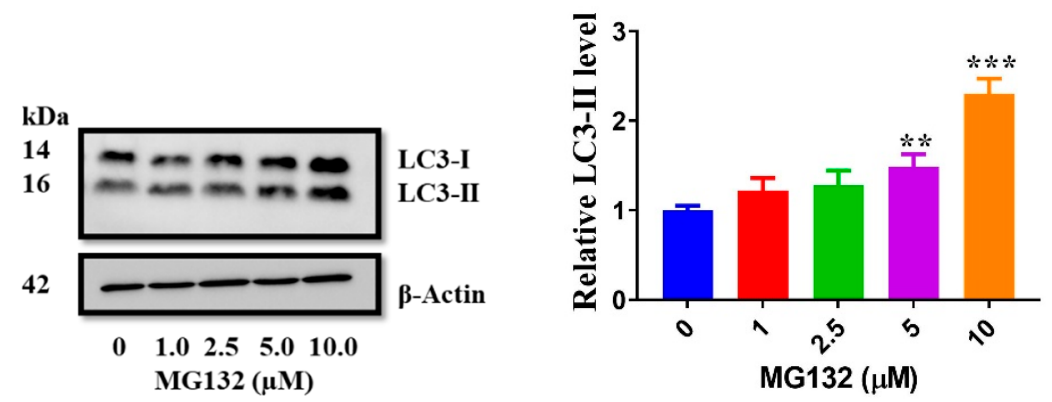

(A)
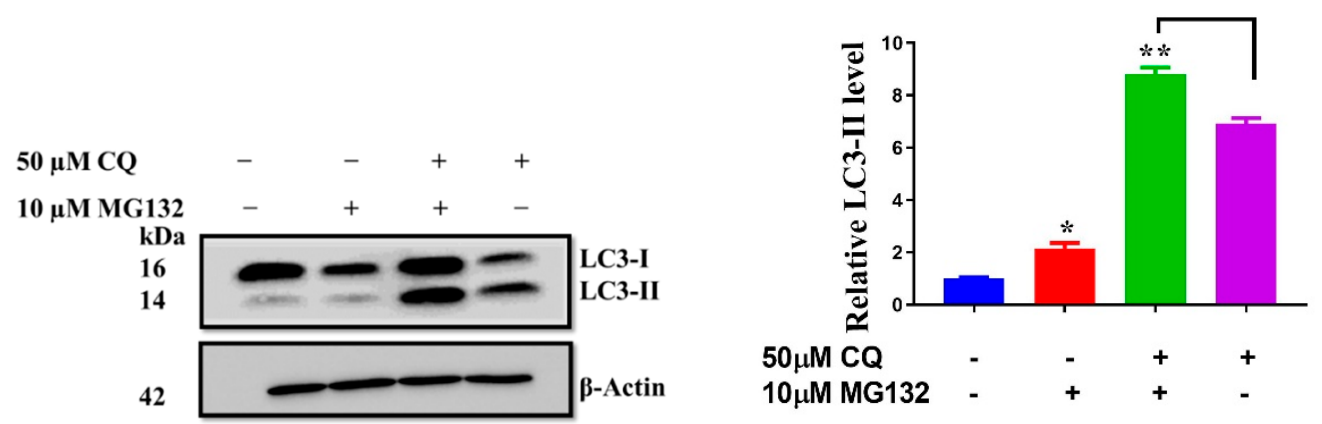

(B)
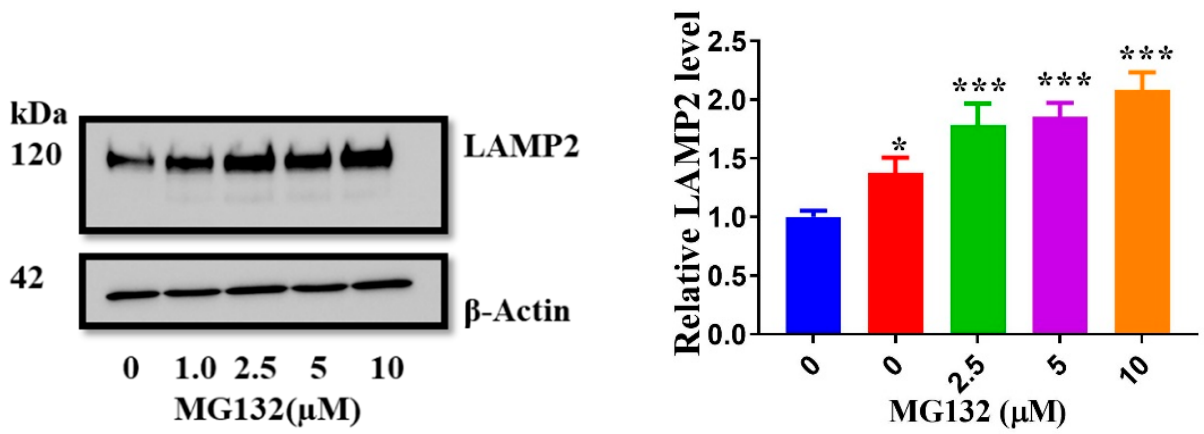

(C)

Figure 7. MG132 upregulates autophagy and LAMP2 expression in human RPE cells. (A) LC3-II levels increased in ARPE-19 cells after treatment with MG132 for $5 \mathrm{~h}$. (B) LC3-II levels in cells incubated with chloroquine for $8 \mathrm{~h}$ followed by incubating with MG132 for $5 \mathrm{~h}$. (C) LAMP2 levels increased in cells after $5 \mathrm{~h}$ incubation with MG132. Protein levels were normalized with $\beta$-actin and expressed as a ratio of the control. Data represent the mean (+SD) of 3 independent experiments of 3 replicates each. Statistical analysis using one-way ANOVA followed by Dunnett's or Sidak's multiple comparisons test. ${ }^{*} p<0.05,{ }^{* *} p<0.01,{ }^{* * *} p<0.001$, significant difference relative to the controls.

Pre-treatment of RPE cells with MG132 ameliorated the toxic effects of $25 \mu \mathrm{M} \mathrm{HQ}$. Specifically, HQ-induced apoptosis, protein carbonylation, and mitochondrial depolar- 
ization were significantly reduced with MG132 pre-treatment (Figure 8A), supporting its protection against HQ-induced oxidative damage. The lowest dose of MG132 (i.e., $2.5 \mu \mathrm{M}$ ) most effectively reduced HQ-induced apoptosis likely because MG132, at higher doses, had a pro-apoptotic effect itself.
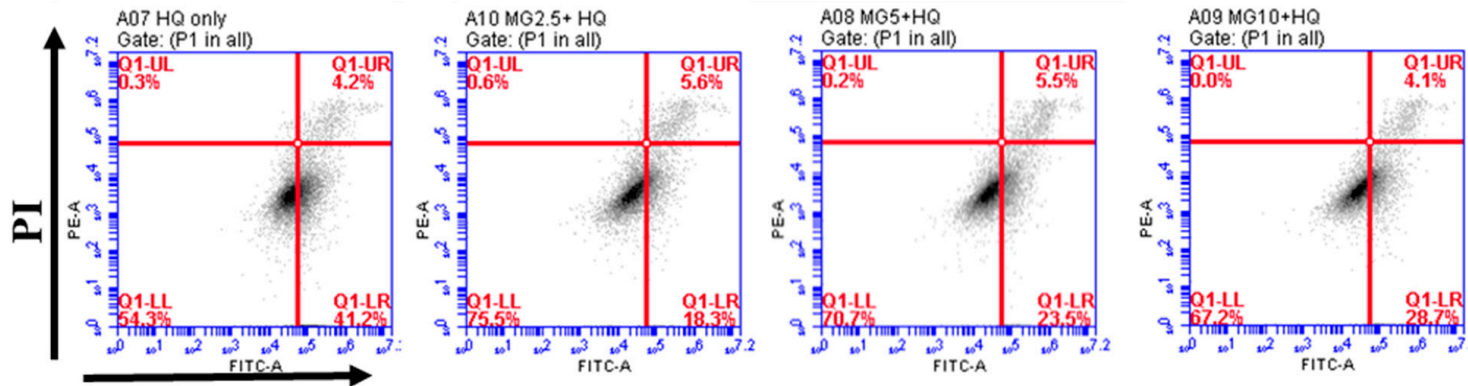

AV FITC

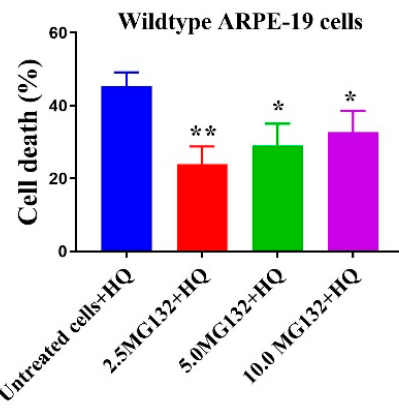

(A)
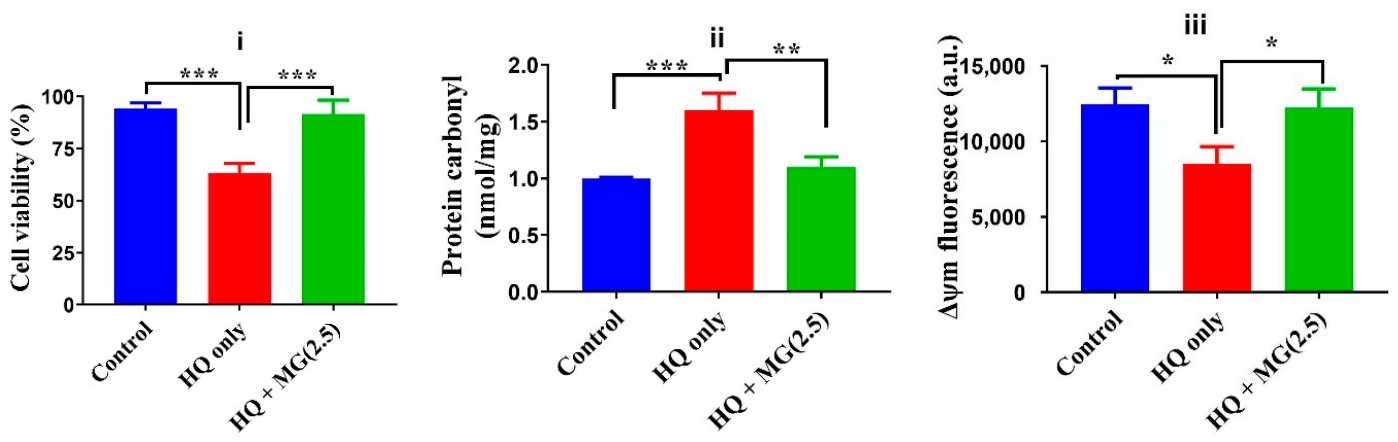

(B)
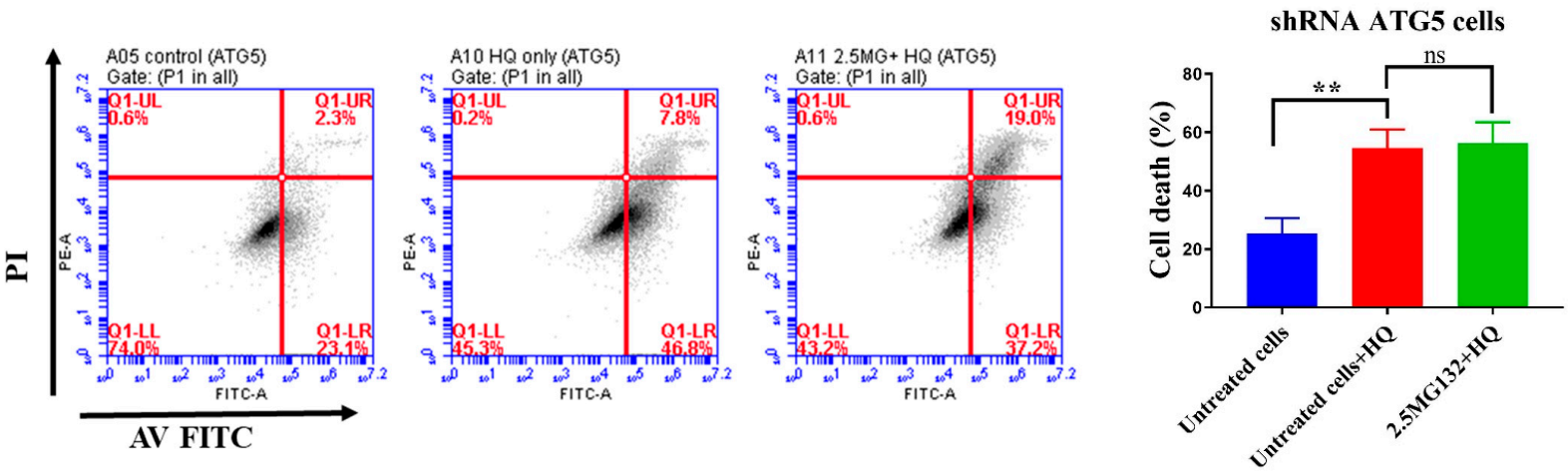

(C)

Figure 8. MG132 protects against hydroquinone-induced oxidative damage and apoptosis in autophagy competent cells. 
(A) Flow cytometry using annexin V-FITC/PI staining in cells treated with MG132 or vehicle (ethanol) for $3 \mathrm{~h}$ before incubation with $25 \mu \mathrm{M} H Q$ for $2 \mathrm{~h}$. (B) Measures of cell viability, protein carbonyl level, and mitochondrial membrane potential in cells pretreated with $2.5 \mu \mathrm{M} \mathrm{MG} 132$ or vehicle for $3 \mathrm{~h}$ before incubation with $25 \mu \mathrm{M} H Q$ for $2 \mathrm{~h}$. (C) Autophagy inhibition following transfection of shRNA against ATG5 caused loss of MG132-mediated protection against HQ-induced apoptotic damage in cells. Data represent the mean (+SD) of 3 independent experiments of 3 replicates each. Statistical analysis using one-way ANOVA followed by Sidak or Dunnett's multiple comparison test. ${ }^{*} p<0.05,{ }^{* *} p<0.01,{ }^{* * *} p<0.001$, significant difference relative to the control.

To confirm that the cytoprotective effects of MG132 were mediated through increased autophagosomal flux, autophagy-defective cells expressing shRNA against ATG5 (Supplementary Materials) were used for the additional experiment. In autophagy-deficient cells, the cytoprotective effect of MG132 against HQ-toxicity was completely lost with a higher number of the HQ- and M132-treated cells progressing from early to late apoptosis relative to cells treated only with HQ (Figure $8 \mathrm{C}$ ). Thus, in the absence of compensatory upregulation of the ALP, proteasome inhibition with MG132 in itself does not confer any protection against HQ-induced toxicity [8].

\section{Discussion}

Oxidative damage induced by hydroquinone affects different cells in the body, contributing to several human diseases. The RPE is a specialized epithelium interfaced between the neuroretina and choriocapillaris. This layer is critical in the maintenance of retinal homeostasis due to its multifunctional roles, which include the transport of nutrient and metabolic waste between the neuroretina and choriocapillaris, the re-isomerization of visual pigments involved in phototransduction, phagocytosing of shed photoreceptor outer segments, and its protection against photooxidation [49,50]. The present study confirmed earlier work on the RPE's relative resistance to oxidative stress from $\mathrm{H}_{2} \mathrm{O}_{2}$ and relative vulnerability to $\mathrm{HQ}[14,15]$. We further investigated the mechanisms involved in hydroquinone-induced RPE oxidative damage because insight into such mechanisms may allow the formulation of therapeutic strategies for RPE protection and potential for the treatment of AMD. This study highlights the central role of the ALP in the response of RPE to HQ-induced oxidative stress. We demonstrated that $\mathrm{HQ}$ impaired lysosomal function and autophagy via lysosomal alkalization and disruption of lysosomal membrane integrity. These events led to the accumulation of damaged proteins, mitochondrial dysfunction, and RPE cell apoptosis. Our results also provided evidence that safeguarding lysosomes was an effective interventional approach to preventing HQ-induced autophagy dysfunction and oxidative damage in RPE cells.

\subsection{Autophagy and Its Protective Role in Oxidative Stress}

Autophagy, in general, can act either as a pro-life or pro-death mechanism; hence, its role in AMD development could be inhibitory or progressive [51]. The antioxidative role of autophagy, however, is one of the pathways contributing to the promotion of cell survival under stressful conditions. Emerging evidence demonstrates the protective role of autophagy in several oxidative stress-linked neurodegenerative disorders, including Alzheimer's disease, Parkinson's disease, Huntington's disease, and motor neuron diseases [52]. Oxidative stress causes protein damage and undermines mitochondrial quality control mechanisms, while autophagy exerts protective effects by eliminating toxic protein aggregates and defective mitochondria, thereby restoring cell and tissue homeostasis [53]. In this study, HQ-induced autophagy deficits in RPE cells, leading to autophagosome accumulation, protein oxidation, mitochondrial dysfunction, and apoptosis. The findings of the present in vitro study mirror the post-mortem findings in human donors with AMD, which include toxic protein aggregation, mitochondria defects, and poorly degraded autophagic substrates in the RPE [53]. In addition, chronic HQ exposure of malignant tumors and cancer cell lines of human origin demonstrate a central role of autophagy in promoting cell resistance against chemotherapy [54-56]. Autophagy inhibition usually 
led to the loss of their resistance against anticancer treatments, leading to apoptosis in HQ-induced cancer cells [54-56]. However, upregulation of autophagy and cytoprotection in cancer cells hints at a different role of HQ in the development of cancers relative to AMD development. Due to the similarities of cellular pathology observed in HQ-treated RPE cell culture and AMD, we believe that the findings of lysosomal dysfunction in this study are also relevant to the understanding of AMD pathogenesis. Hence, interventions that improve lysosomal function and mitigate autophagy inhibition in RPE cells may also hold potential as therapeutic strategies in AMD management.

\subsection{Lysosomal Dysfunction Underlying HQ-Induced Autophagy Deficit and RPE Damage}

AMD donor eyes show evidence of dysfunctional autophagy and decline in lysosomal activity, believed to be crucial in drusen formation and the pathogenesis of the disease [57]. Our results pointed to lysosomal dysfunction as the cause of the autophagy deficit in HQ-induced oxidative stress. This is consistent with recent emphases on the importance of lysosomal homeostasis in promoting autophagy and cell survival under oxidative stress [58,59]. Lysosomal degradation of a substrate in RPE cells is dependent on lysosomal hydrolases with acidic $\mathrm{pH}$ optima between 4.5 and $5.2[42,43]$. A low luminal $\mathrm{pH}$ requires an intact lysosomal membrane barrier composed of ubiquitous highly glycosylated, lysosomeassociated membrane proteins including LAMP1 and LAMP2 [60]. LAMP2 also regulates the intracellular transport of hydrolases to lysosomes after sorting from the trans-Golgi network, and lysosomal membrane fusion with autophagosomes [60]. While dysregulated LAMP1 expression does not cause apparent lysosomal defects, LAMP2 deficiency impairs lysosomal degradation and autophagy and is implicated in Danon disease [60]. Therefore, based on the HQ-mediated decline in LAMP2 and cathepsin D levels and the alkalizing effect of HQ on lysosomes, the results of this study supported that loss of lysosomal membrane integrity and lysosomal function were critical events in mediating the toxicity of HQ in RPE cells $[57,58,60]$. Similar harmful effects of HQ on lysosomes as observed with HQ have also been observed with prooxidants including paraquat and lipofuscin, substances that inhibit autophagy and phagocytosis [58,59].

We ruled out the possibility of transcriptional downregulation of autophagy by demonstrating that HQ induced overexpression of TFEB and the activation of autophagy genes. The overexpression of TFEB in cells exposed to HQ may be a compensatory mechanism to induce lysosomal biogenesis [61]. However, TFEB activation may not reverse the autophagy deficit because it primarily controls the transcriptional activation of the ALP, whereas HQ may also affect the ALP at the protein level, in addition to its downstream lysosomal alkalizing effect.

\subsection{Role of Autophagy and UPS Crosstalk in HQ-Induced Oxidative Stress}

Under oxidative stress in RPE cells, previous reports indicated that the UPS is compromised, implicating the downregulation of UPS in RPE damage [47]. Our data, on the contrary, showed increased proteasome activity when human RPE cells were exposed to HQ. It is known, however, that the effect of an oxidant on the UPS depends on the severity of ROS levels and whether the exposure is transient/sustained [6]. Hence, the differential effects between $\mathrm{HQ}$ and $\mathrm{H}_{2} \mathrm{O}_{2}$ on proteasome activity may be related to differences in their ROS generating capacities, which was much lower with $\mathrm{HQ}$ treatment for the tested concentrations. Furthermore, we demonstrated that proteasome inhibition with MG132 stabilized lysosomes, induced autophagy, and protected RPE cells from oxidative damage. Thus, the evidence in this study suggested compensatory crosstalk between the UPS and autophagy and supported the potential benefit of proteasome inhibition with MG132 in the management of AMD.

\subsection{Conclusions}

Overall, this study identified lysosomal dysfunction and autophagy deficits as the mechanisms underlying HQ-induced oxidative damage in human RPE. From our data, 
therefore, we propose treatments targeted at promoting lysosomal homeostasis and autophagy via proteasome inhibition, as potential therapeutic strategies in the management of AMD. While this strategy is feasible in our experiments, further studies to ascertain the criteria and the extent to which the cross-talk between autophagy and proteasome activity could be adequately altered without any harmful effects are warranted since increased proteasome inhibition or overstimulated autophagy with higher doses of MG132 offered no cytoprotection.

\section{Materials and Methods}

\subsection{Cell Culture and Treatment}

Human RPE cells (ARPE-19 cell line, ATCC ${ }^{\circledR}$ CRL2302 ${ }^{\mathrm{TM}}$ ) were cultured with Dulbecco's modified Eagle's medium (DMEM)/F12 (Sigma-Aldrich, St. Louis, MO, USA) containing 10\% fetal bovine serum (Invitrogen-Gibco, Grand Island, NY, USA) and 1\% penicillin/streptomycin antibiotic mixture (Thermal Fisher Scientific, Rockford, IL, USA). The cell line was thoroughly tested for mycoplasma using three different methods-agar culture (direct) method, Hoechst DNA stain (indirect) method, and PCR assay (lot \#: 70022669, ATCC $\left.^{\circledR}\right)$. The medium was renewed every three days, and the cells were incubated at $37{ }^{\circ} \mathrm{C}$ in a humidified atmosphere containing $5 \% \mathrm{CO}_{2}$.

For experiments, cells grown to $80 \%$ confluency between passage 11 and 16 were used as recommended by the supplier. After $24 \mathrm{~h}$ of serum starvation, cells were incubated with $\mathrm{HQ}$ (hydroquinone, $\mathrm{H} 9003$, Sigma-Aldrich), $\mathrm{H}_{2} \mathrm{O}_{2}$ (hydrogen peroxide $30 \%$, 107209, Merck Millipore, Burlington, MA, USA), CQ (chloroquine diphosphate salt, C6628, Sigma-Aldrich), MG132 (M8699, Sigma-Aldrich), or a combination of these treatments. The whole-cell lysate was prepared using ice-cold $1 \times$ RIPA lysis buffer [0.5 M Tris- $\mathrm{HCl}(\mathrm{pH} 7.4)$, $1.5 \mathrm{M} \mathrm{NaCl}, 2.5 \%$ deoxycholic acid, 10\% NP-40, and $10 \mathrm{mM}$ EDTA (Millipore)] containing 1:100 protease inhibitor cocktail (Thermo Scientific, Waltham, MA, USA) unless otherwise stated. Bio-Rad Protein Assay was used to quantify sample protein concentrations (Bio-Rad Laboratories).

\subsection{Cell Viability Assay}

The Trypan blue dye exclusion assay was used to assess cell viability. Briefly, ARPE-19 cells with a seeding density of $1 \times 10^{6}$ cells/well cultured in 6-well plates were incubated with treatments as desired in triplicate. After trypsinization and centrifugation at $1500 \mathrm{rpm}$ for $5 \mathrm{~min}$, cells were stained with $0.4 \%$ trypan blue solution (Sigma-Aldrich, T6146) to quantify viability as a percentage of the control.

\subsection{Intracellular ROS Assay}

Cells were plated on 96-well plates $\left(1.5 \times 10^{4}\right.$ cells/well $)$ or $35-\mathrm{mm}$ MatTek glassbottom dishes (MatTek Corp., Ashland, MA, USA) $\left(1 \times 10^{6}\right.$ cells/dish) overnight. On the next day, cells were rinsed with PBS and incubated with $5 \mu \mathrm{M}$ 5-(and-6)-chloromethyl-2' , $^{\prime}$ dichlorodihydrofluorescein diacetate (CM-H2DCFDA, C6827, Invitrogen, NY, USA) for $1 \mathrm{~h}$ in the dark at $37^{\circ} \mathrm{C}$. Afterward, cells were treated with $\mathrm{HQ}$ or $\mathrm{H}_{2} \mathrm{O}_{2}$ for $2 \mathrm{~h}$ or MG132 for $5 \mathrm{~h}$. Intracellular ROS accumulation leads to increased fluorescence of cells due to the conversion of the cell-permeable dye from the non-fluorescent dichlorodihydrofluorescein (DCFH) to a highly fluorescent dichlorofluorescein (DCF) form within cells. A Clariostar microplate reader (BMG Labtech, Offenburg, Germany) or confocal microscopy (Eclipse Ti2-E, Nikon Instruments Europe B.V., Amsterdam, The Netherlands) was used to assess the fluorescence intensity at excitation/emission wavelengths of 483/530 nm. Data were normalized with Hoechst stain.

\subsection{Live Cell Intra-Lysosomal pH Measurement}

The ratiometric fluorescent dye LysoSensor ${ }^{\mathrm{TM}}$ Yellow/Blue DND-160 (cat \# L7545, Thermo Fisher Scientific) was used to measure the $\mathrm{pH}$ of lysosomes. This dye permeates live cells and accumulates in the lysosomes where it shifts fluorescence from blue to yellow 
depending on the acidity. For quantification of the intra-lysosomal $\mathrm{pH}$, cells plated on a black 96-well plate $\left(1.5 \times 10^{4}\right.$ cells/well $)$ and treated as designated were loaded with $1 \mu \mathrm{M}$ LysoSensor ${ }^{\mathrm{TM}}$ Yellow/Blue DND-160 for $5 \mathrm{~min}$. A pH calibration curve using $\mathrm{pH}$ values of 4.0, 4.5, 5.0, 5.5, 6.0, and 7.0 was then generated by incubating cells with standard buffers of known $\mathrm{pH}$ containing $10 \mu \mathrm{M}$ nigericin for $10 \mathrm{~min}$, as described previously [62]. The ionophore nigericin equilibrates $\mathrm{pH}$ across cells so that the final ion gradients depend on the experimental conditions [63]. Fluorescence intensity was measured in triplicate using the Varioskan LUX Multimode Microplate Reader (Thermo Fisher Scientific) for light emitted at $440 \mathrm{~nm}$ and $540 \mathrm{~nm}$ with reference excitation wavelengths of $329 \mathrm{~nm}$ and $384 \mathrm{~nm}$, respectively. The lysosomal $\mathrm{pH}$ of samples was determined with the help of the calibration curve.

\subsection{Mitochondrial Membrane Potential}

Mitochondrial membrane potential was measured using the tetramethylrhodamine, ethyl ester (TMRE) potentiometric probe according to the manufacturer's protocol (cat \# 87917, Sigma-Aldrich). In brief, ARPE-19 cells seeded at approximately $1 \times 10^{4}$ cells/well on a 96-well plate were grown for $48 \mathrm{~h}$. Cells treated as designated or with the negative control, carbonyl cyanide 4-(trifluoromethoxy) phenylhydrazone (FCCP), for $10 \mathrm{~min}$ [64] were incubated with $400 \mathrm{nM}$ TMRE dye at $37^{\circ} \mathrm{C}$ for $15 \mathrm{~min}$, followed by repeat rinsing with $1 \times \mathrm{PBS} / 0.2 \%$ BSA. Fluorescence at excitation/emission wavelengths of 549/575 nm was quantified using a Clariostar microplate reader (BMG Labtech). Data were normalized with Hoechst stain fluorescence.

\subsection{Mitochondrial Morphology Using Confocal Microscopy}

An assessment of the mitochondrial morphology was performed using the fluorescent mitochondrial marker MitoTracker Green FM (M7514, Thermo Fischer Scientific) which is stable and unaffected by changes in mitochondrial membrane potential [65]. Briefly, cells were seeded onto $35 \mathrm{~mm}$ MatTek glass-bottom dishes $\left(1 \times 10^{6} \mathrm{cells} /\right.$ dish), cultured for $48 \mathrm{~h}$, and treated as indicated, followed by loading with $50 \mathrm{nM}$ MitoTracker Green FM. After a 15-min incubation in the dark, cells were rinsed and visualized in a serum-free medium under an inverted confocal microscope (Eclipse Ti2-E, Nikon Instruments Europe B.V., Amsterdam, The Netherlands) using a $63 \times$ magnification with excitation/emission wavelengths of $490 / 516 \mathrm{~nm}$.

\subsection{Flow Cytometry with Annexin V-FITC/PI}

Cellular apoptosis was assessed using flow cytometry and the Annexin V Apoptosis Detection Kit (Cat \# 640914, BioLegend Inc., San Diego, CA, USA) using the manufacturerrecommended propidium iodide (PI) double staining approach. Briefly, trypsinized cells were rinsed twice, and cells were suspended at a density of $1 \times 10^{6} \mathrm{cells} / \mathrm{mL}$ incubated with $5 \mu \mathrm{L}$ Annexin V-FITC for 10 minutes in the dark at room temperature, followed by incubation with $10 \mu \mathrm{L}$ PI for 5 minutes and dilution with $400 \mu \mathrm{L}$ binding buffer for flow cytometry (BD FACSVia Flow Cytometer, BD Biosciences, Franklin Lakes, NJ, USA). Unstained cells in the presence of dyes (FITC-, PI-) are viable; the FITC-stained cells (FITC+, PI-) are undergoing early apoptosis, and double-stained cells (FITC+, PI+) indicate late apoptosis or necrosis [66].

\subsection{Autophagosome Accumulation Assessment by GFP-LC3 Puncta}

Expression of GFP-LC3 in ARPE-19 cells at a cell density of $1.0 \times 10^{6}$ cells was performed by transfection with $2.5 \mu \mathrm{g}$ pEGFP-LC3 plasmid (Addgene plasmid \# 24920) using Lipofectamine 3000 (Invitrogen) for 24 hours in a $35 \mathrm{~mm}$ confocal dish. After pharmacological treatment, autophagy flux was assessed by quantifying the GFP-LC3 puncta number per cell using an inverted confocal microscope (Eclipse Ti2-E, Nikon Instruments Europe B.V., Amsterdam, The Netherlands) with a $63 \times$ objective. For each treatment condition, the average GFP-LC3 puncta per cell were determined by counting 30 cells. 


\subsection{Protein Carbonyl Assay}

Spectrophotometry measurement of the protein carbonyl level was performed using an ELISA kit following the manufacturer's instructions (Oxiselect ${ }^{\mathrm{TM}}$ protein carbonyl, STA-310, Cell Biolabs, San Diego, CA, USA). Briefly, lysate from cells at cell density of $1.5 \times 10^{6}$ cells/well treated as designated in a 6-well plate was incubated with $1 \%$ streptomycin sulfate (S9137, Sigma-Aldrich), and protein extract at a concentration of $10 \mu \mathrm{g} / \mathrm{mL}$ was adsorbed onto a 96-well plate for $2 \mathrm{~h}$ at $37^{\circ} \mathrm{C}$, and protein carbonyls were then derivatized to DNP hydrazine. Finally, samples were incubated with an antiDNP antibody followed by HRP conjugated secondary antibody, and the absorbance was measured at $450 \mathrm{~nm}$ wavelength using a microplate Reader plate (Ao, Azure Biosystems Inc., Dublin, CA, USA).

\subsection{Proteasome Activity Assay}

Proteasome activity was measured using a fluorogenic 7-amino-4-methyl coumarin (AMC)-tagged substrate kit to detect chymotrypsin-like activity following the manufacturer's protocol (Cat \#: K245, Biovision, San Francisco, CA, USA). Briefly, lysate from treated cells was extracted using $25 \mathrm{mM}$ Tris- $\mathrm{HCl}$ buffer and loaded onto a 96-well plate in duplicate for incubation with the fluorescent substrate at $37^{\circ} \mathrm{C}$ for $30 \mathrm{~min}$ in the presence of MG132 (proteasome inhibitor) or without (as control). Due to the chymotrypsin-like activity of proteasomes, highly fluorescent AMC is released from the AMC-tagged peptide substrate. Fluorescence intensity was then measured at excitation/emission of 350/440 nm using a Clariostar microplate reader (BMG Labtech). Results were normalized to the protein concentration of samples.

\subsection{Western Blot}

A $30 \mu \mathrm{g}$ denatured protein sample was loaded onto each well of a separating gel for SDS-PAGE electrophoresis (10\% SDS-PAGE gels). Electro-transfer of proteins from gel to an Immobilon-FL PVDF membrane (Millipore) took $2 \mathrm{~h}$ in prechilled buffer with cold pack using $250 \mathrm{~mA}$. Membrane blocking involved incubation with $5 \%$ non-fat milk in Tris-buffered saline containing 0.05\% Tween 20 (Bio-Rad Laboratories) for $1 \mathrm{~h}$ at room temperature. Primary antibody incubation with anti-LC3 (NB100-2220, Novus Biologicals, Littleton, CO, dilution 1:1000), anti-LAMP2 (sc-18822, Santa Cruz Biotechnology, Dallas, TX, USA, dilution 1:2000), anti-cathepsin D (sc-377299, Santa Cruz Biotechnology, dilution 1:500), anti-TFEB (D2O7D, Cell Signaling Technology, Davers, MA, USA, 1:500), and $\beta$-actin (AC-15, Thermo Fisher Scientific, dilution 1:2000) was performed overnight at $4{ }^{\circ} \mathrm{C}$. The washed membrane was incubated with horseradish peroxidase HRP-conjugated secondary antibodies including anti-mouse IgG $(\mathrm{H}+\mathrm{L}, \mathrm{A} 16066)$ and anti-rabbit IgG $(\mathrm{H}+\mathrm{L}, \mathrm{A} 16110$; Thermo Fisher Scientific, dilution 1:2000) for $1 \mathrm{~h}$, washed, and developed by incubation with ECL substrate solutions for $5 \mathrm{~min}$. The western blot images were acquired using the Chemidoc MP Imaging System (Bio-Rad, Hercules, CA, USA).

\subsection{2. shRNA Knockdown of ATG5}

Stable knockdown of ATG5 in ARPE-19 cells was achieved using lentiviral delivery of short hairpin RNA (shRNA). HEK293T cells seeded in a $10 \mathrm{~cm}$ culture dish $\left(3 \times 10^{6}\right.$ cell $/$ dish) were transfected with a lentiviral vector coding a scrambled shRNA plasmid (Addgene plasmid \# 1864) or ATG5 shRNA, TRC numbers: TRCN0000151474 (Sigma-Aldrich) using Lipofectamine 2000 (Invitrogen). The transfection lasted for $8 \mathrm{~h}$ followed by incubation in a fresh medium for $48 \mathrm{~h}$. Virions were collected and precipitated overnight using PEG before filtering with a $0.45 \mu \mathrm{m}$ filter. ARPE-19 cells were incubated with virions for $48 \mathrm{~h}$ for cell transduction, followed by treatment with puromycin $(1.0 \mu \mathrm{g} / \mathrm{mL})$ for 10 days for the identification of transduced, puromycin-resistant colonies. 


\subsection{RNA Extraction and Quantitative RT-PCR}

cDNA was synthesized (High Capacity cDNA Reverse Transcription Kit, Thermo Fisher Scientific) from $1 \mu \mathrm{g}$ total RNA extracted using Trizol (Invitrogen) as described previously [18]. The reaction mixture used in quantitative RT-PCR contained $2 \mu \mathrm{L}$ cDNA template, $5 \mu \mathrm{L}$ LightCycler 480 SYBR Green I Master mix (Roche Diagnostics, Mannheim, Germany), $1 \mu \mathrm{L}$ nuclease-free water, and $1 \mu \mathrm{L}$ of gene-specific primers. Primer sequences were as follows: ATG5 forward: $5^{\prime}$-AAGCTGTTTCGTCCTGTGGC- $3^{\prime}$ and ATG5 reverse: 5'-CCGGGTAGCTCAGATGTTCA-3'; ATG7 forward: $5^{\prime}$-CGTTGCCCACAGCATCATCTTC$3^{\prime}$ and ATG7 reverse: $5^{\prime}$-TCCCATGCCTCCTTTCTGGTTC-3'; $\beta$-actin forward: $5^{\prime}$-CCAAC CGCGAGAAGATGA- $3^{\prime}$ and $\beta$-actin reverse: $5^{\prime}$-CCAGAGGCGTACAGGGATAG- $3^{\prime}$. The conditions used to run the LightCycler ${ }^{\circledR} 480$ Instrument II (Roche Diagnostics) included denaturation at $95^{\circ} \mathrm{C}$ for $5 \mathrm{~min}$, followed by 40 cycles at $95^{\circ} \mathrm{C}$ for $30 \mathrm{~s}, 60^{\circ} \mathrm{C}$ for $30 \mathrm{~s}$, and $72{ }^{\circ} \mathrm{C}$ for $30 \mathrm{~s}$. Fold changes were calculated using the change in the Cycle threshold $(\Delta \Delta \mathrm{CT})$ method. $\beta$-actin was used for normalizing the expressions of other genes following the validation of its stability by the coefficient of variation analysis (CV) in ARPE-19 cells under normal and treatment conditions.

\subsection{Data Analysis}

GraphPad Prism (Graphpad Software Inc., San Deigo, CA, USA) was used for analyzing data. All data are presented as the mean $\pm \mathrm{SD}$. In determining the difference between treatments, an unpaired $t$-test was used for two treatment groups, and one-way ANOVA followed by Sidak's/Dunnett's multiple comparison post hoc tests was performed when three or more treatment groups were involved. $p<0.05$ indicates statistical significance.

Supplementary Materials: The following are available online at https:/ /www.mdpi.com/article/10 .3390/ijms22169042/s1, Figure S1: Transfection of cells with lentivirus particles coding shRNA ATG5 or scrambled RNA.

Author Contributions: D.Y.-Y.T. and S.A. designed the study, experiments were performed by S.A., S.-W.S., C.H.-I.L. and K.P.C., data analysis and interpretation were done by S.A., D.Y.-Y.T., F.P., C.-H.T. and S.-W.S., the manuscript and figures were prepared by S.A., the manuscript was critically reviewed and revised by D.Y.-Y.T., S.-W.S., F.P., C.-H.T. and H.H.-L.C. All authors have read and agreed to the published version of the manuscript.

Funding: This work was funded by the RGC Hong Kong Ph.D. Fellowship UGC/GEN/456/08, UGC/456/09, RGC General Research Fund (151060/18M), The Government of the Hong Kong Special Administrative Region \& Innovation and Technology Fund, PolyU Central Research Grant UAG1, UAHD, PolyU Dean's Reserve (ZVN2), and Henry G. Leong Endowed Professorship in Elderly Vision Health.

Data Availability Statement: All data supporting the results of the study have been presented as figures.

Acknowledgments: We are grateful to KK Li (School of Optometry, PolyU) for helping with general laboratory work. Further, we thank Hoyin Chow and other staff of the University Research Facility in Life Science, PolyU, for technical assistance in the operations of the LightCycler 480 Real-Time PCR System. An abstract of this paper was presented at the Association for Research in Vision and Ophthalmology Conference, Honolulu, Hawaii, the USA, on 28 April 2018, as a poster presentation with preliminary findings.

Conflicts of Interest: The authors declare no conflict of interest. The funders had no role in the design of the study; in the collection, analyses, or interpretation of data; in the writing of the manuscript, or in the decision to publish the results. 


\section{References}

1. Liguori, I.; Russo, G.; Curcio, F.; Bulli, G.; Aran, L.; Della-Morte, D.; Gargiulo, G.; Testa, G.; Cacciatore, F.; Bonaduce, D.; et al. Oxidative stress, aging, and diseases. Clin. Interv. Aging 2018, 13, 757. [CrossRef]

2. Islam, M.T. Oxidative stress and mitochondrial dysfunction-linked neurodegenerative disorders. Neurol. Res. 2017, 39, 73-82. [CrossRef]

3. Fedorova, M.; Bollineni, R.C.; Hoffmann, R. Protein carbonylation as a major hallmark of oxidative damage: Update of analytical strategies. Mass Spectrom. Rev. 2014, 33, 79-97. [CrossRef]

4. Giordano, S.; Darley-Usmar, V.; Zhang, J. Autophagy as an essential cellular antioxidant pathway in neurodegenerative disease. Redox Biol. 2014, 2, 82-90. [CrossRef]

5. Birben, E.; Sahiner, U.M.; Sackesen, C.; Erzurum, S.; Kalayci, O. Oxidative stress and antioxidant defense. World Allergy Organ. J. 2012, 5, 9-19. [CrossRef]

6. Shang, F.; Taylor, A. Ubiquitin-proteasome pathway and cellular responses to oxidative stress. Free Radic. Biol. Med. 2011, 51, 5-16. [CrossRef]

7. Nam, T.; Han, J.H.; Devkota, S.; Lee, H.-W. Emerging Paradigm of Crosstalk between Autophagy and the Ubiquitin-Proteasome System. Mol. Cells 2017, 40, 897-905. [CrossRef]

8. Ji, C.H.; Kwon, Y.T. Crosstalk and Interplay between the Ubiquitin-Proteasome System and Autophagy. Mol. Cells 2017, 40, 441. [CrossRef]

9. Enguita, F.J.; Leitão, A.L. Hydroquinone: Environmental Pollution, Toxicity, and Microbial Answers. BioMed Res. Int. 2013, 2013, 1-14. [CrossRef]

10. Abokyi, S.; To, C.H.; Lam, T.T.; Tse, D.Y. Central Role of Oxidative Stress in Age-Related Macular Degeneration: Evidence from a Review of the Molecular Mechanisms and Animal Models. Oxid. Med. Cell. Longev. 2020, 2020, 7901270. [CrossRef]

11. Lauwen, S.; de Jong, E.K.; Lefeber, D.J.; den Hollander, A.I. Omics Biomarkers in Ophthalmology. Investig. Opthalmology Vis. Sci. 2017, 58, BIO88-98. [CrossRef]

12. Chakravarthy, U.; Augood, C.; Bentham, G.C.; de Jong, P.T.V.M.; Rahu, M.; Seland, J.; Soubrane, G.; Tomazzoli, L.; Topouzis, F.; Vingerling, J.R.; et al. Cigarette Smoking and Age-Related Macular Degeneration in the EUREYE Study. Ophthalmology 2007, 114, 1157-1163. [CrossRef]

13. Deisinger, P.J.; Hill, T.S.; English, J.C. Human exposure to naturally occurring hydroquinone. J. Toxicol. Environ. Health 1996, 47, 31-46. [CrossRef]

14. Espinosa-Heidmann, D.G.; Suner, I.J.; Catanuto, P.; Hernandez, E.P.; Marin-Castano, M.E.; Cousins, S.W. Cigarette smoke-related oxidants and the development of sub-RPE deposits in an experimental animal model of dry AMD. Investig. Ophthalmol. Vis. Sci. 2006, 47, 729-737. [CrossRef]

15. Marin-Castaño, M.E.; Striker, G.E.; Alcazar, O.; Catanuto, P.; Espinosa-Heidmann, D.G.; Cousins, S.W. Repetitive nonlethal oxidant injury to retinal pigment epithelium decreased extracellular matrix turnover in vitro and induced Sub-RPE deposits in vivo. Investig. Ophthalmol. Vis. Sci. 2006, 47, 4098-4112. [CrossRef]

16. Wang, A.L.; Lukas, T.J.; Yuan, M.; Du, N.; Handa, J.T.; Neufeld, A.H. Changes in retinal pigment epithelium related to cigarette smoke: Possible relevance to smoking as a risk factor for age-related macular degeneration. PLoS ONE 2009, 4, e5304. [CrossRef]

17. Cao, S.; Walker, G.B.; Wang, X.; Cui, J.Z.; Matsubara, J.A. Altered cytokine profiles of human retinal pigment epithelium: Oxidant injury and replicative senescence. Mol. Vis. 2013, 19, 718-728.

18. Abokyi, S.; wan Shan, S.; To, C.; Chan, H.H.; Tse, D.Y. Autophagy Upregulation by the TFEB Inducer Trehalose Protects against Oxidative Damage and Cell Death Associated with NRF2 Inhibition in Human RPE Cells. Oxid. Med. Cell. Longev. 2020, 2020, 1-18. [CrossRef]

19. Lu, L.; Hackett, S.F.; Mincey, A.; Lai, H.; Campochiaro, P.A. Effects of different types of oxidative stress in RPE cells. J. Cell. Physiol. 2006, 206, 119-125. [CrossRef]

20. Gough, D.R.; Cotter, T.G. Hydrogen peroxide: A Jekyll and Hyde signalling molecule. Cell Death Dis. 2011, 2, e213. [CrossRef]

21. Deisinger, P.J.; English, J.C. Bioavailability and metabolism of hydroquinone after intratracheal instillation in male rats. Drug Metab. Dispos. 1999, 27, 442-448.

22. Smith, M.T.; Zhang, L.; Jeng, M.; Wang, Y.; Guo, W.; Duramad, P.; Hubbard, A.E.; Hofstadler, G.; Holland, N.T. Hydroquinone, a benzene metabolite, increases the level of aneusomy of chromosomes 7 and 8 in human CD34-positive blood progenitor cells. Carcinogenesis 2000, 21, 1485-1490. [CrossRef]

23. Kerzic, P.J.; Liu, W.S.; Pan, M.T.; Fu, H.; Zhou, Y.; Schnatter, A.R.; Irons, R.D. Analysis of hydroquinone and catechol in peripheral blood of benzene-exposed workers. Chem. Biol. Interact. 2010, 184, 182-188. [CrossRef]

24. Halliwell, B.; Clement, M.V.; Ramalingam, J.; Long, L.H. Hydrogen Peroxide. Ubiquitous in Cell Culture and In Vivo? IUBMB Life 2001, 50, 251-257. [CrossRef]

25. Munro, D.; Treberg, J.R. A radical shift in perspective: Mitochondria as regulators of reactive oxygen species. J. Exp. Biol. 2017, 220, 1170-1180. [CrossRef]

26. Karbowski, M.; Youle, R.J. Dynamics of mitochondrial morphology in healthy cells and during apoptosis. Cell Death Differ. 2003, 10, 870-880. [CrossRef] 
27. Zorova, L.D.; Popkov, V.A.; Plotnikov, E.J.; Silachev, D.N.; Pevzner, I.B.; Jankauskas, S.S.; Zorov, S.D.; Babenko, V.A.; Zorov, D.B. Functional Significance of the Mitochondrial Membrane Potential. Biochem. Suppl. Ser. A Membr. Cell Biol. 2018, 12, 20-26. [CrossRef]

28. Yang, P.; Shao, Z.; Besley, N.A.; Neal, S.E.; Buehne, K.L.; Park, J.; Karageozian, H.; Karageozian, V.; Ryde, I.T.; Meyer, J.N.; et al. Risuteganib Protects against Hydroquinone-induced Injury in Human RPE Cells. Investig. Opthalmology Vis. Sci. 2020, 61, 35. [CrossRef]

29. Carlsson, S.R.; Simonsen, A. Membrane dynamics in autophagosome biogenesis. J. Cell Sci. 2015, 128, 193-205. [CrossRef]

30. Mizushima, N.; Yoshimori, T. How to interpret LC3 immunoblotting. Autophagy 2007, 3, 542-545. [CrossRef]

31. Yoshii, S.R.; Mizushima, N. Monitoring and measuring autophagy. Int. J. Mol. Sci. 2017, 18, 1865. [CrossRef]

32. Mauthe, M.; Orhon, I.; Rocchi, C.; Zhou, X.; Luhr, M.; Hijlkema, K.J.; Coppes, R.P.; Engedal, N.; Mari, M.; Reggiori, F. Chloroquine inhibits autophagic flux by decreasing autophagosome-lysosome fusion. Autophagy 2018, 14, 1435-1455. [CrossRef]

33. Chen, P.M.; Gombart, Z.J.; Chen, J.W. Chloroquine treatment of ARPE-19 cells leads to lysosome dilation and intracellular lipid accumulation: Possible implications of lysosomal dysfunction in macular degeneration. Cell Biosci. 2011, 1, 1-10. [CrossRef]

34. He, Y.; Li, S.; Zhang, W.; Dai, W.; Cui, T.; Wang, G.; Gao, T.; Li, C. Dysregulated autophagy increased melanocyte sensitivity to H2O2-induced oxidative stress in vitiligo. Sci. Rep. 2017, 7, srep42394. [CrossRef]

35. Szatmári-Tóth, M.; Kristóf, E.; Veréb, Z.; Akhtar, S.; Facskó, A.; Fésüs, L.; Kauppinen, A.; Kaarniranta, K.; Petrovski, G. Clearance of autophagy-associated dying retinal pigment epithelial cells - a possible source for inflammation in age-related macular degeneration. Cell Death Dis. 2016, 7, e2367. [CrossRef]

36. Settembre, C.; Di Malta, C.; Polito, V.A.; Arencibia, M.G.; Vetrini, F.; Erdin, S.; Erdin, S.U.; Huynh, T.; Medina, D.; Colella, P.; et al. TFEB links autophagy to lysosomal biogenesis. Science 2011, 332, 1429-1433. [CrossRef]

37. Settembre, C.; De Cegli, R.; Mansueto, G.; Saha, P.K.; Vetrini, F.; Visvikis, O.; Huynh, T.; Carissimo, A.; Palmer, D.; Jürgen Klisch, T.; et al. TFEB controls cellular lipid metabolism through a starvation-induced autoregulatory loop. Nat. Cell Biol. 2013, 15, 647-658. [CrossRef] [PubMed]

38. Hubert, V.; Peschel, A.; Langer, B.; Gröger, M.; Rees, A.; Kain, R. LAMP-2 is required for incorporating syntaxin-17 into autophagosomes and for their fusion with lysosomes. Biol. Open 2016. [CrossRef] [PubMed]

39. Cui, L.; Zhao, L.-P.; Ye, J.-Y.; Yang, L.; Huang, Y.; Jiang, X.-P.; Zhang, Q.; Jia, J.-Z.; Zhang, D.-X.; Huang, Y. The Lysosomal Membrane Protein Lamp2 Alleviates Lysosomal Cell Death by Promoting Autophagic Flux in Ischemic Cardiomyocytes. Front. Cell Dev. Biol. 2020, 8, 31. [CrossRef]

40. Zaidi, N.; Maurer, A.; Nieke, S.; Kalbacher, H. Cathepsin D: A cellular roadmap. Biochem. Biophys. Res. Commun. 2008, 376, 5-9. [CrossRef] [PubMed]

41. Eskelinen, E.L.; Illert, A.L.; Tanaka, Y.; Schwarzmann, G.; Blanz, J.; Von Figura, K.; Saftig, P. Role of LAMP-2 in lysosome biogenesis and autophagy. Mol. Biol. Cell 2002, 13, 3355-3368. [CrossRef]

42. Guha, S.; Baltazar, G.C.; Coffey, E.E.; Tu, L.A.; Lim, J.C.; Beckel, J.M.; Patel, S.; Eysteinsson, T.; Lu, W.; O’Brien-Jenkins, A.; et al Lysosomal alkalinization, lipid oxidation, and reduced phagosome clearance triggered by activation of the P2X7 receptor. FASEB J. 2013, 27, 4500-4509. [CrossRef]

43. Liu, J.; Lu, W.; Reigada, D.; Nguyen, J.; Laties, A.M.; Mitchell, C.H. Restoration of Lysosomal pH in RPE Cells from Cultured Human and ABCA4 - / - Mice: Pharmacologic Approaches and Functional Recovery. Investig. Opthalmology Vis. Sci. 2008, 49, 772. [CrossRef]

44. Wang, D.; Xu, Q.; Yuan, Q.; Jia, M.; Niu, H.; Liu, X.; Zhang, J.; Young, C.Y.; Yuan, H. Proteasome inhibition boosts autophagic degradation of ubiquitinated-AGR2 and enhances the antitumor efficiency of bevacizumab. Oncogene 2019, 38, 3458-3474. [CrossRef]

45. Li, C.; Wang, X.; Li, X.; Qiu, K.; Jiao, F.; Liu, Y.; Kong, Q.; Liu, Y.; Wu, Y. Proteasome Inhibition Activates Autophagy-Lysosome Pathway Associated With TFEB Dephosphorylation and Nuclear Translocation. Front. Cell Dev. Biol. 2019, 7, 170. [CrossRef]

46. Zhang, X.; Zhou, J.; Fernandes, A.F.; Sparrow, J.R.; Pereira, P.; Taylor, A.; Shang, F. The Proteasome: A Target of Oxidative Damage in Cultured Human Retina Pigment Epithelial Cells. Investig. Opthalmology Vis. Sci. 2008, 49, 3622. [CrossRef]

47. Fernandes, A.F.; Zhou, J.; Zhang, X.; Bian, Q.; Sparrow, J.; Taylor, A.; Pereira, P.; Shang, F. Oxidative Inactivation of the Proteasome in Retinal Pigment Epithelial Cells. J. Biol. Chem. 2008, 283, 20745-20753. [CrossRef] [PubMed]

48. Brojatsch, J.; Lima, H.; Kar, A.K.; Jacobson, L.S.; Muehlbauer, S.M.; Chandran, K.; Diaz-Griffero, F. A Proteolytic Cascade Controls Lysosome Rupture and Necrotic Cell Death Mediated by Lysosome-Destabilizing Adjuvants. PLoS ONE 2014, 9 , e95032. [CrossRef] [PubMed]

49. Sparrrow, J.R.; Hicks, D.; Hamel, C.P. The Retinal Pigment Epithelium in Health and Disease. Curr. Mol. Med. 2010. [CrossRef] [PubMed]

50. Strauss, O. The Retinal Pigment Epithelium in Visual Function. Physiol. Rev. 2005, 85, 845-881. [CrossRef]

51. Kaarniranta, K.; Tokarz, P.; Koskela, A.; Paterno, J.; Blasiak, J. Autophagy regulates death of retinal pigment epithelium cells in age-related macular degeneration. Cell Biol. Toxicol. 2017, 33, 113-128. [CrossRef]

52. Galluzzi, L.; Bravo-San Pedro, J.M.; Levine, B.; Green, D.R.; Kroemer, G. Pharmacological modulation of autophagy: Therapeutic potential and persisting obstacles. Nat. Rev. Drug Discov. 2017, 16, 487-511. [CrossRef]

53. Ferrington, D.A.; Sinha, D.; Kaarniranta, K. Defects in retinal pigment epithelial cell proteolysis and the pathology associated with age-related macular degeneration. Prog. Retin. Eye Res. 2016, 51, 69-89. [CrossRef] 
54. Qian, S.; Han, Y.; Shi, Y.; Xu, W.; Zhu, Y.; Jiang, S.; Chen, Y.; Yu, Z.; Zhang, S.; Yang, Y.; et al. Benzene induces haematotoxicity by promoting deacetylation and autophagy. J. Cell. Mol. Med. 2019, 23, 1022-1033. [CrossRef]

55. Chiou, J.T.; Huang, C.H.; Lee, Y.C.; Wang, L.J.; Shi, Y.J.; Chen, Y.J.; Chang, L. Sen Compound C induces autophagy and apoptosis in parental and hydroquinone-selected malignant leukemia cells through the ROS/p38 MAPK/AMPK/TET2/FOXP3 axis. Cell Biol. Toxicol. 2020. [CrossRef] [PubMed]

56. Xu, L.; Liu, J.; Chen, Y.; Yun, L.; Chen, S.; Zhou, K.; Lai, B.; Song, L.; Yang, H.; Liang, H.; et al. Inhibition of autophagy enhances Hydroquinone-induced TK6 cell death. Toxicol. Vitr. 2017. [CrossRef] [PubMed]

57. Wang, A.L.; Lukas, T.J.; Yuan, M.; Du, N.; Tso, M.O.; Neufeld, A.H. Autophagy and Exosomes in the Aged Retinal Pigment Epithelium: Possible Relevance to Drusen Formation and Age-Related Macular Degeneration. PLoS ONE 2009, 4, e4160. [CrossRef]

58. Pivtoraiko, V.N.; Stone, S.L.; Roth, K.A.; Shacka, J.J. Oxidative stress and autophagy in the regulation of lysosome-dependent neuron death. Antioxidants Redox Signal. 2009, 11, 481-496. [CrossRef] [PubMed]

59. Pascua-Maestro, R.; Diez-Hermano, S.; Lillo, C.; Ganfornina, M.D.; Sanchez, D. Protecting cells by protecting their vulnerable lysosomes: Identification of a new mechanism for preserving lysosomal functional integrity upon oxidative stress. PLOS Genet. 2017, 13, e1006603. [CrossRef]

60. Schwake, M.; Schröder, B.; Saftig, P. Lysosomal Membrane Proteins and Their Central Role in Physiology. Traffic 2013, 14, 739-748. [CrossRef] [PubMed]

61. Settembre, C.; Ballabio, A. TFEB regulates autophagy: An integrated coordination of cellular degradation and recycling processes. Autophagy 2011, 7, 1379-1381. [CrossRef]

62. Ma, L.; Ouyang, Q.; Werthmann, G.C.; Thompson, H.M.; Morrow, E.M. Live-cell Microscopy and Fluorescence-based Measurement of Luminal pH in Intracellular Organelles. Front. Cell Dev. Biol. 2017, 5. [CrossRef] [PubMed]

63. Nicholls, D.G.; Ferguson, S.J. Ion Transport across Energy-Conserving Membranes. In Bioenergetics; Elsevier: Amsterdam, The Netherlands, 2013; pp. 13-25.

64. Perry, S.W.; Norman, J.P.; Barbieri, J.; Brown, E.B.; Gelbard, H.A. Mitochondrial membrane potential probes and the proton gradient: A practical usage guide. Biotechniques 2011, 50, 98-115. [CrossRef]

65. Puleston, D. Detection of Mitochondrial Mass, Damage, and Reactive Oxygen Species by Flow Cytometry. Cold Spring Harb. Protoc. 2015, 2015, pdb.prot086298. [CrossRef] [PubMed]

66. Henry, C.M.; Hollville, E.; Martin, S.J. Measuring apoptosis by microscopy and flow cytometry. Methods 2013, 61, 90-97. [CrossRef] [PubMed] 